Supporting Information

\title{
Influence of Water and Enzyme on the Post-Transition State Bifurcation
}

\section{of NgnD-Catalyzed Ambimodal [6+4]/[4+2] Cycloaddition}

Xin Wang ${ }^{\ddagger 1-2}$, Chun Zhang ${ }^{\ddagger 3}$, Yaoyukun Jiang ${ }^{4}$, Wen Wang ${ }^{8}$, Yuan Zhou ${ }^{2}$, Yu Chen ${ }^{1}$, Bo Zhang ${ }^{8}$, Ren Xiang Tan ${ }^{8}$, Hui Ming Ge**, Zhongyue J. Yang**-7, Yong Liang*1

${ }^{1}$ State Key Laboratory of Coordination Chemistry, Jiangsu Key Laboratory of Advanced Organic Materials, Chemistry and Biomedicine Innovation Center, School of Chemistry and Chemical Engineering, Nanjing University, Nanjing, 210023, China

${ }^{2}$ Henan-Macquarie University Joint Centre for Biomedical Innovation, School of Life Sciences, Henan University, Kaifeng, Henan, 475004, China

${ }^{3}$ School of Pharmaceutical Sciences, Jiangnan University, Wuxi, 214122, China

${ }^{4}$ Department of Chemistry, Vanderbilt University, Nashville, Tennessee 37235, United States

${ }^{5}$ Vanderbilt Institute of Chemical Biology, Vanderbilt University, Nashville, Tennessee 37235, United States

${ }^{6}$ Center for Structural Biology, Vanderbilt University, Nashville, Tennessee 37235, United States

${ }^{7}$ Data Science Institute, Vanderbilt University, Nashville, Tennessee 37235, United States

${ }^{8}$ State Key Laboratory of Pharmaceutical Biotechnology, Institute of Functional Biomolecules, School of Life Sciences, Nanjing University, Nanjing 210023, China

*Correspondence to: zhongyue.yang@vanderbilt.edu; hmge@nju.edu.cn; yongliang@nju.edu.cn

$\left[{ }^{\ddagger}\right]$ These authors contributed equally to this work

\section{Table of Contents}

I. Computational Methodologies.

II. Experimental Procedures..

III. Supplementary Figures and Tables..

Figure S1. The CA_distance clustering analysis of NgnD-TS from MD simulation. . 55

Figure S2. The CA_distance clustering analysis of NgnD-R from MD simulation. .S6

Figure S3. Analyze the different results of reactants and transition states by cluster model.......S7

Figure S4. Interactions of reactants and transition states in enzyme during MD simulation......S12

Figure S5. Typical trajectories for the formation of adducts in the gas phase and water...........S17

Figure S6. Distribution of time gaps for the $[6+4] /[4+2]$ cycloaddition.................................. S17

Figure S7. Computed dipole moments and molecular volumes...................................... S18

Figure S8. Distribution of bonds 2 and 3 for TS-1 in implicit water and diethylether............. S18

Table S1. The energy of NgnD-TS and NgnD-R cluster................................................. S19

Table S2. The calculated free energy barriers in enzyme and in water....................................S19

Table S3. Molecular volumes for the $[6+4] /[4+2]$ adducts and TS-1....................................S19

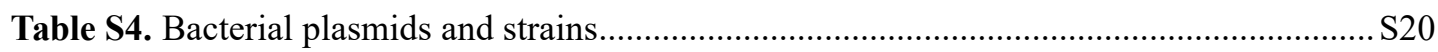

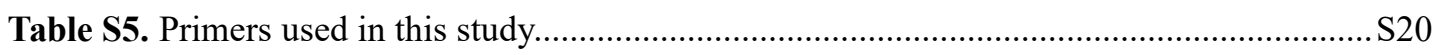

IV. B3LYP-D3/6-31G(d) calculated Cartesian coordinates...................................................S21

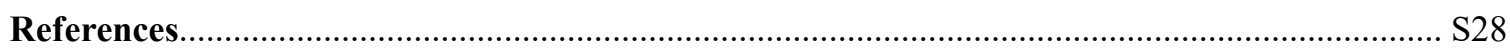




\section{Computational Methodologies}

Density functional theory (DFT) calculations were performed with the Gaussian 09 program package. ${ }^{1}$ The geometry optimizations of minima and transition states involved were carried out at the B3LYP-D3 level of theory ${ }^{2}$ with the 6-31G(d) basis set. The vibrational frequencies were computed at the same level to check whether each optimized structure is an energy minimum or a transition state and to evaluate its zero-point vibration energy (ZPVE) and thermal corrections at $298 \mathrm{~K}$. The conformer with lowest energy was presented in the Supporting Information. Solvation energies were computed at the M06-2X level of theory ${ }^{3}$ with the $6-311+\mathrm{G}(\mathrm{d}, \mathrm{p})$ basis set using the gas-phase optimized structures and the CPCM model ${ }^{4,5}$ in water. Quasi-classical molecular dynamics simulations in gas on a B3LYP-D3/6-31G(d) energy surface were initiated in the region of the potential energy surface near TS-1. The real normal mode of TS-1 was given its zero-point energy (ZPE) plus a Boltzmann sampling of the thermal energy available at $298 \mathrm{~K}$ with a random phase. The trajectories were integrated in time (the step length for integration was $1 \mathrm{fs}$ ) in both the forward and backward directions until either the $[6+4]$ or $[4+2]$ adduct was formed or reactant was reformed.

We continue our previous work $^{6}$ : we started with the monomer structure of $\mathrm{NgnD}$ and performed molecular dynamics (MD) simulations on the protein in water for $15 \mathrm{~ns}$, which is long enough for equilibration. We found that the size of the pocket (potential active site) reaches its largest at $11 \mathrm{~ns}$, so we took the structure at the end of $11 \mathrm{~ns}$ and docked in the DFT-optimized structures of reactant 1 or transition state TS-1. For the reaction in enzyme, the substrate or TS were docked into the enzyme active site using AutoDock Vina. $^{7}$ The binding mode that ranks best in each case was then used as a starting point for subsequent MD simulations. The docking structures were solvated in a water box using AmberTools $16 .^{8}$

Classical MD was performed using Amber 16 on the substrate and the transition state for $500 \mathrm{~ns}$ in water and in NgnD. The molecular models constructed in water and in NgnD were used for MD simulations with RESP $^{9}$ charges assigned on 1 and TS-1. General Amber Force Field (GAFF) ${ }^{10}$ was used for the substrate and the transition state structures. The FF99SBildn ${ }^{11}$ force field was used for protein residues. In water and in $\mathrm{NgnD}$, the system was minimized for 20000 steps, and gradually heated to $300 \mathrm{~K}$ and then equilibrated for $100 \mathrm{ps}$ under constant $\mathrm{T}$ and $\mathrm{P}$. Production run was conducted for $500 \mathrm{~ns}$ under constant volume and temperature. During the classical MD on the TS-1, restraining potentials of $200 \mathrm{kcal} / \mathrm{mol} / \AA^{2}$ were applied to the reaction coordinates in the TS-1. One hundred snapshots were taken in the last $100 \mathrm{~ns}$ with $1 \mathrm{~ns}$ interval to form an ensemble of TS-1. QM/MM calculations were performed by using QM/MM method (ONIOM scheme: B3LYP-D3/6-31G(d)//Amber ) within Gaussian 16. ${ }^{12}$

Environment-perturbed transition-state sampling (EPTSS) method $^{13}$ : The cycloaddition TSs was treated by quantum mechanics (QM) method (B3LYP-D3/6-31G(d)) while the waters and enzyme were treated by molecular mechanics (MM) method (TIP3P (water) and FF99SBildn force field (enzyme)). Reactive trajectory simulations were initiated from 60 randomly selected TS-1 snapshots optimized in water and in NgnD. For each snapshot, normal mode sampling was conducted on the TS-1 at $300 \mathrm{~K}$ to obtain 4 sets of 
coordinates and momenta in a quasiclassical manner. This allows the sampling of TS-1 geometries and velocities on the TS-1 dividing surface in water and in NgnD. The coordinates and momenta for the solvent molecules or protein residues in the snapshot were adopted from classical MD simulations (saved in rst files). The sampling gave coordinates and momenta of transition state geometries for 240 trajectories. They are saved in geoPlusVel files. During the sampling, the bound modes were the real frequencies of the TS-1, and the transition vector was the reaction coordinate. The modes whose frequencies are smaller than $100 \mathrm{~cm}^{-1}$ were removed to prevent anharmonicity. They were partially revised from Singleton's Progdyn package. ${ }^{14}$ The geoPlusVel files were then transformed to the rst files. These files are used to initiate reaction dynamics trajectories. These trajectories were propagated forward and backward with 1 fs step size using QM/MM method with AMBER Gaussian interface. ${ }^{15}$ In each direction, trajectories were terminated after 100 steps. The total length of each trajectory is 200 fs. The solvent accessible surface area (SASA) for $[6+4] /[4+2]$ adducts was calculated using Shrake and Rupley algorithm implemented in the python library MDTraj. ${ }^{16}$ The probe radius was 1.4 $\AA$ and the surface of each atom was represented by 5000 points. The graphs of $3 \mathrm{D}$ structures were generated using CYLview ${ }^{17}$ and PyMOL (http://www.pymol.org/). GaussView 6.0.16 was used to construct initial structures used in our computations. Schematic diagrams of the interactions between protein and ligands were shown by LigPlot $^{+} .18$

The methods of Principal component (PC) analysis and clustering are as follows. MD simulations were sampling larger amounts of molecular and biomolecular conformations. Being able to qualitatively and quantitatively sift these conformations into meaningful groups was a difficult and important task. Here we adopted two popular techniques, principal component analysis (PCA) and clustering, performing the last $100 \mathrm{~ns}$ dynamic trajectories to identify representative enzyme conformers. Clustering was performed using K-means algorithms. The plots of clustering and PCA were shown in Figure S1. It suggested that the optimal clusters value for NgnD-TS was 6. According to same method, the optimal clusters value for NgnD-R was 4 from the plots of Figure S2. The energies of 20 nearest geometries from the center of each cluster were calculated applying QM/MM method in Gaussian 16. The calculated results were listed in Table S1. We chose the TSCluster5 and RCluster1 with lowest average energy as representative conforms for NgnD-TS and NgnD-R, respectively. 


\section{Experimental Procedures}

\section{General experimental procedures.}

All NMR experiments were run on a Bruker Avance $600 \mathrm{MHz}$ with a cryoprobe or Bruker Avance III $400 \mathrm{MHz}$. High resolution LC-MS analysis was performed on an Agilent 6530 TOF LC-MS spectrometer with a Porshell 120 EC-C18 column $(4.5 \times 50$ $\mathrm{mm}, 2.7 \mu \mathrm{m}$, Agilent Techonologies). Analytical HPLC was performed on an Agilent 1260 HPLC system with a DAD detector equipped with a Porshell 120 (EC-C18, 4.5×50 $\mathrm{mm}, 2.7 \mu \mathrm{m}$, Agilent Techonologies).

\section{Bacterial strains, plasmids, culture conditions and chemicals.}

The strains and plasmids used in this study are listed in Table S4. PCR primers were synthesized by Genscript Biological Technology Co. and listed in Table S5. PCRs were used the Phanta Max Super-Fidelity DNA Polymerase (Vazyme Biotech) to amplification the homologous. The restriction endonucleases were obtained from Thermo Fisher. The genotype of the mutants were identified by $2 \times$ Rapid Taq Master Mix (Vazyme Biotech) with additional 5\% DMSO. DNA gel extraction and plasmid preparation kits were purchased from Omega Bio-Tek. E. coli strains harboring plasmids were grown in LB (Luria-Bertani medium) with appropriate antibiotics, such as apramycin $(50 \mu \mathrm{g} / \mathrm{ml})$, kanamycin $(50 \mu \mathrm{g} / \mathrm{ml})$ or chloramphenicol $(25 \mu \mathrm{g} / \mathrm{ml}) .{ }^{19}$ E. coli ET12567/pUZ8002 was used as the host for intergeneric conjugations.S. seoulensis A01 and mutant strains were cultivated on ISP4 medium at $28^{\circ} \mathrm{C}$ for sporulation. ${ }^{20}$ Biological reagents, chemicals, media and enzymes were purchased from standard commercial sources unless otherwise indicated.

\section{Gene complementation.}

For gene complementation, the fragment containing $n g n D$ was ligated with the linearized pSET152-KasOp* (digested by SpeI and EcoRI), to produce pYL02001. Then, the plasmid pYL02001 was transferred into the E. coli/ET12567(pUZ8002) strain, and further introduced into strain $\operatorname{stm} A B C$ by conjugation to generate strain $\operatorname{stm} A B C:: n g n D$ following the standard procedure described previously. ${ }^{20,21}$

\section{Fermentation and analysis.}

The fermentation was carried out using the same method reported previously. ${ }^{20} \mathrm{In}$ brief, fresh spores of mutant strains were inoculated into $50 \mathrm{ml} \mathrm{TSB}$ medium at $28^{\circ} \mathrm{C}$ and $200 \mathrm{rpm}$ for two days. The seed culture was then inoculated into production medium $(5 \mathrm{~g}$ peptone, $2 \mathrm{~g}$ beef extract, $5 \mathrm{~g}$ glucose, $1.0 \mathrm{~g} \mathrm{~K}_{2} \mathrm{HPO}_{4}, 0.5 \mathrm{~g} \mathrm{FeSO}_{4}$ in 11 water, pH 7.0) at $28^{\circ} \mathrm{C}$ and cultivated for eight days. After cultivation for eight days, the supernatant of the fermentation broth was extracted with ethyl acetate and concentrated into $0.75 \mathrm{ml}$ acetone for HPLC analysis. HPLC was performed using a 23 min solvent gradient system from $10 \%$ to $90 \%$ methanol in water at a flow rate of $0.5 \mathrm{~mL} / \mathrm{min}$. The methanol and water of HPLC were supplemented with $0.1 \%$ formic acid (v/v). 


\section{Supplementary Figures and Tables}
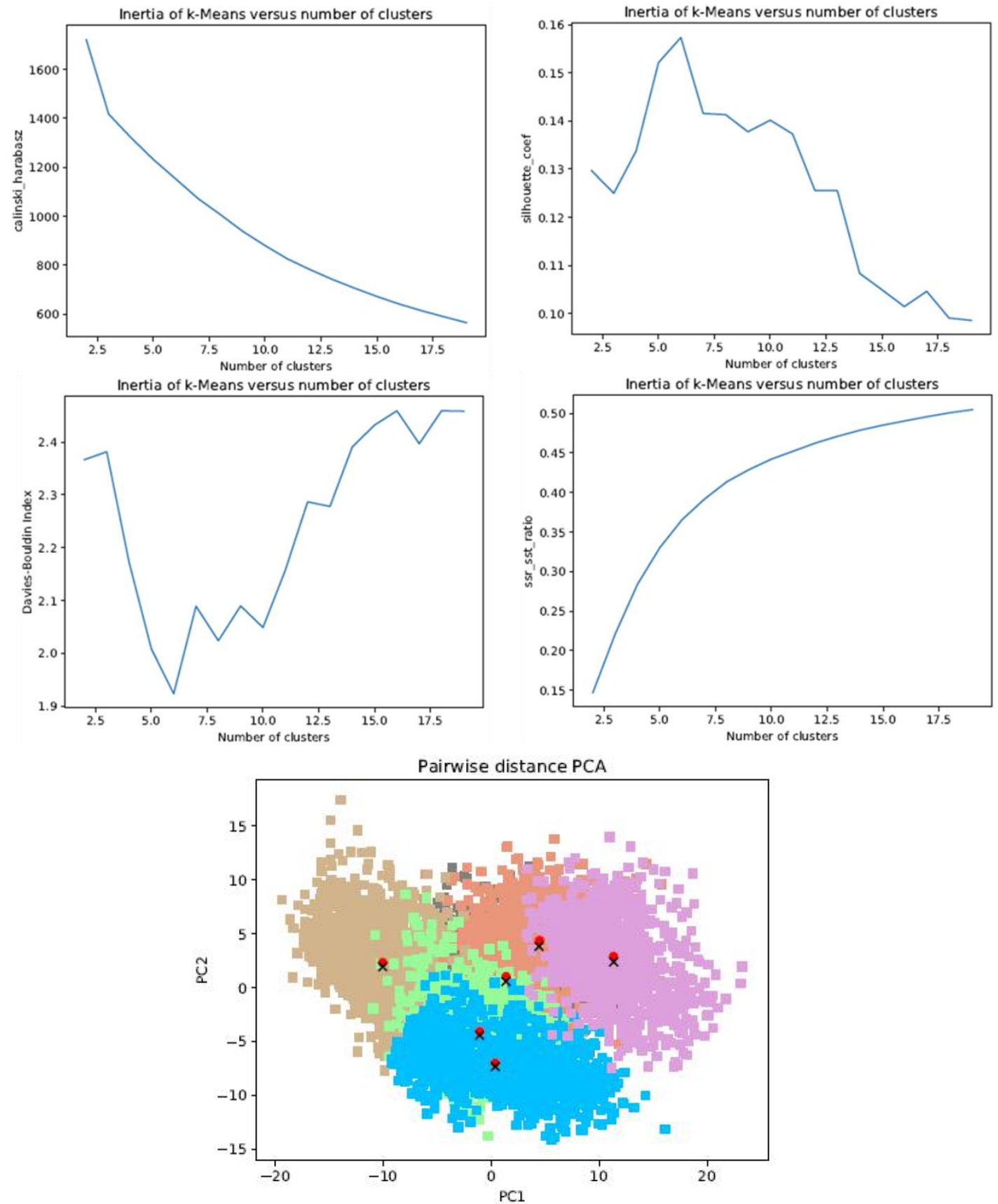

Figure S1. The CA_distance clustering analysis for 10000 conformations of NgnD-TS from MD simulation. 

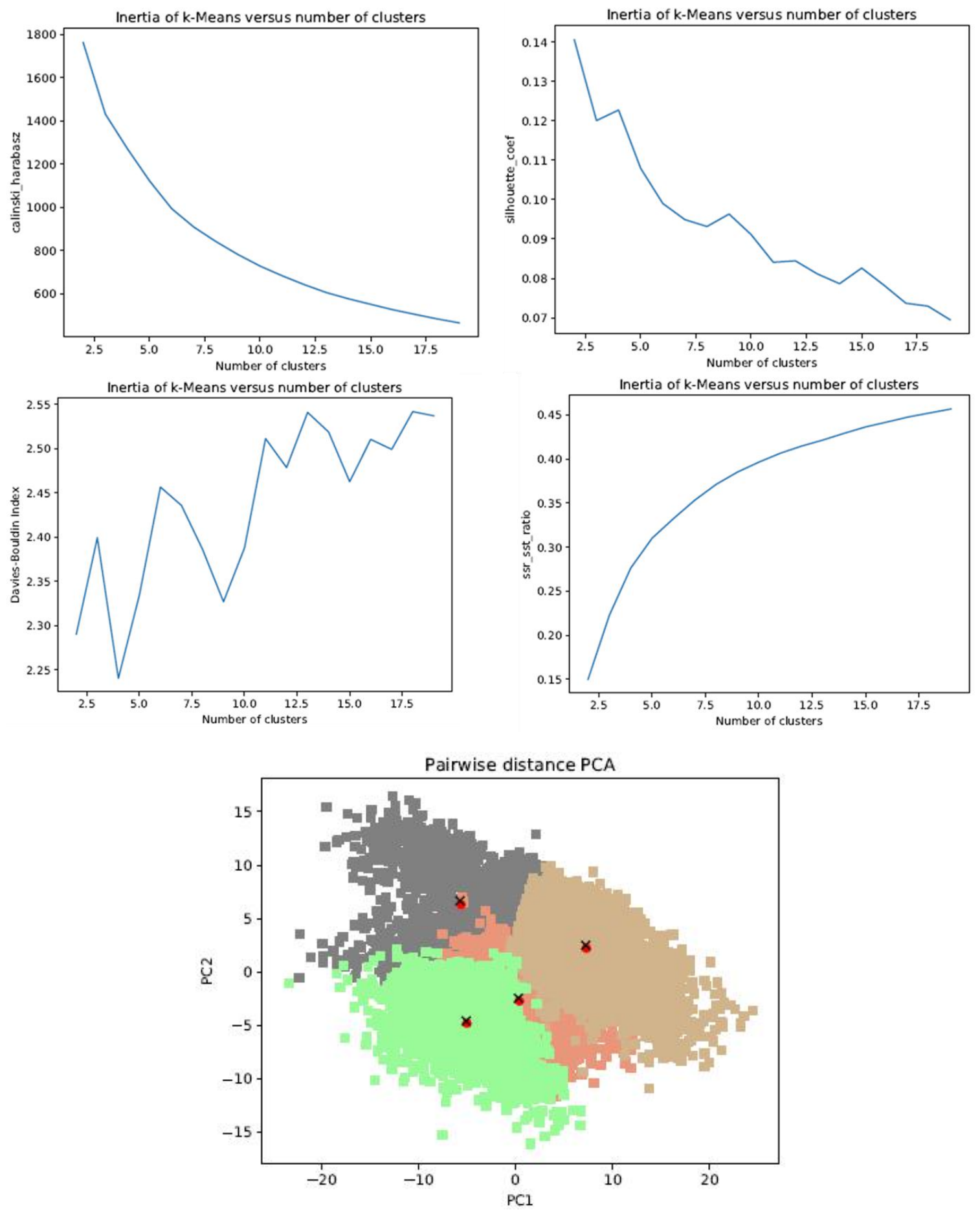

Figure S2. The CA_distance clustering analysis for 10000 conformations of NgnD-R from MD simulation. 


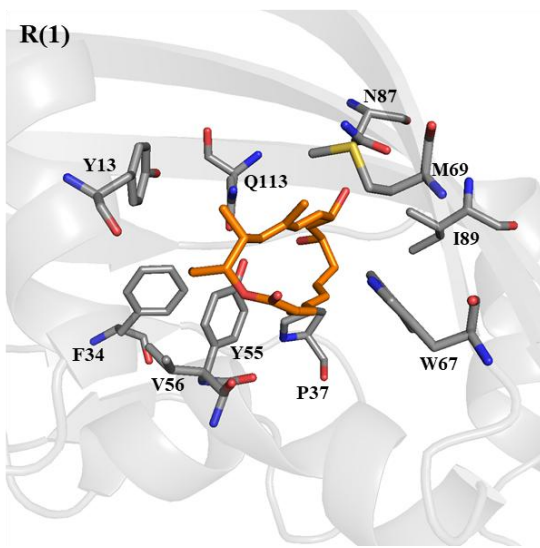

R(2)
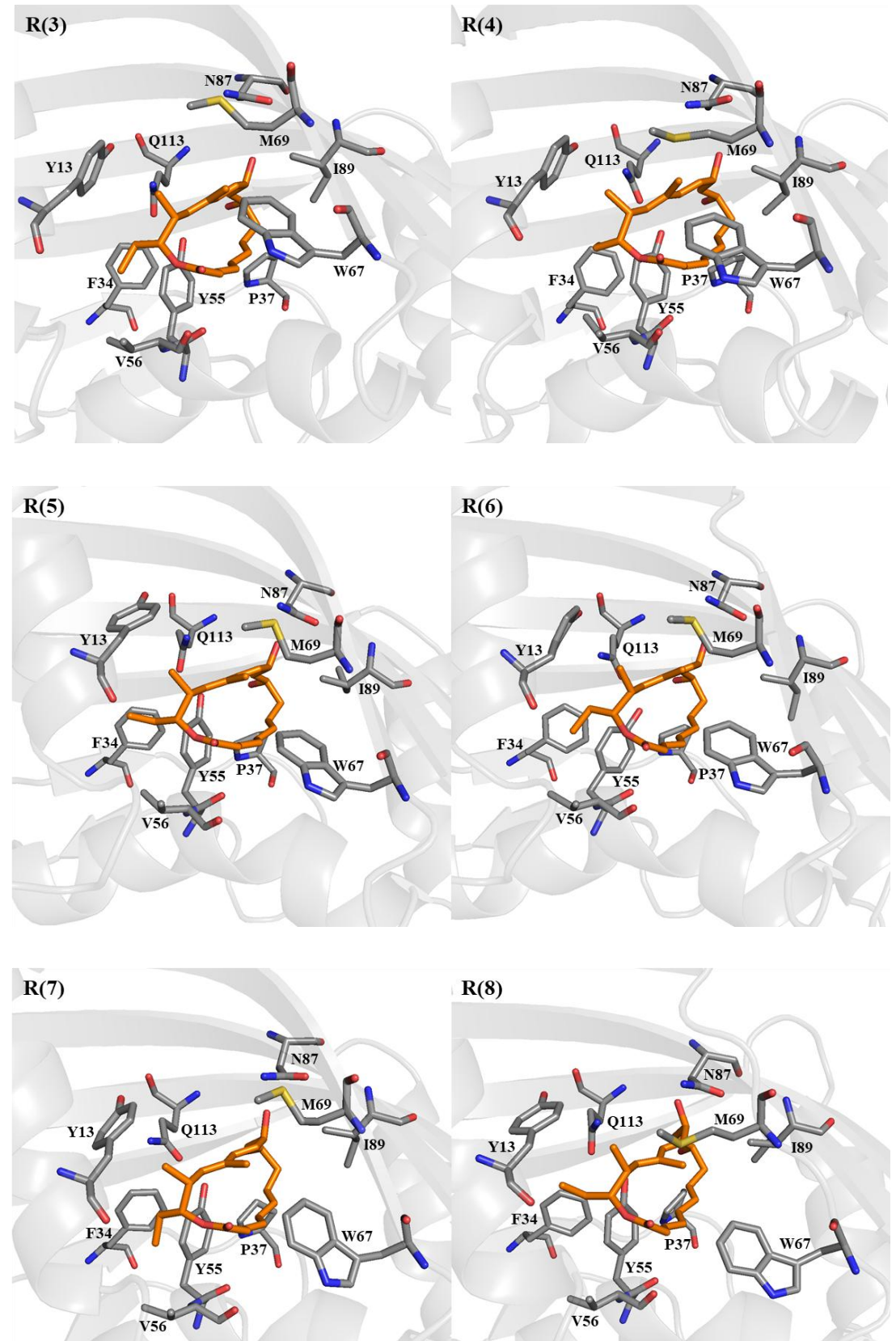

R(8)

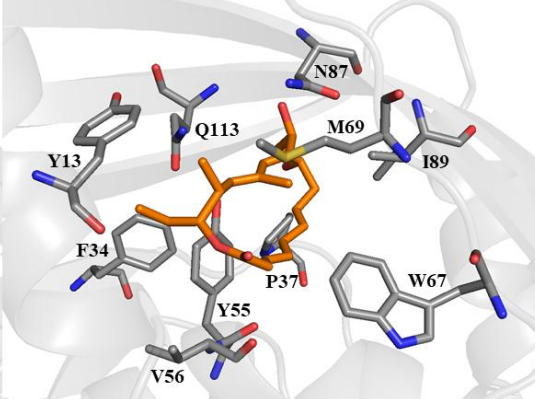



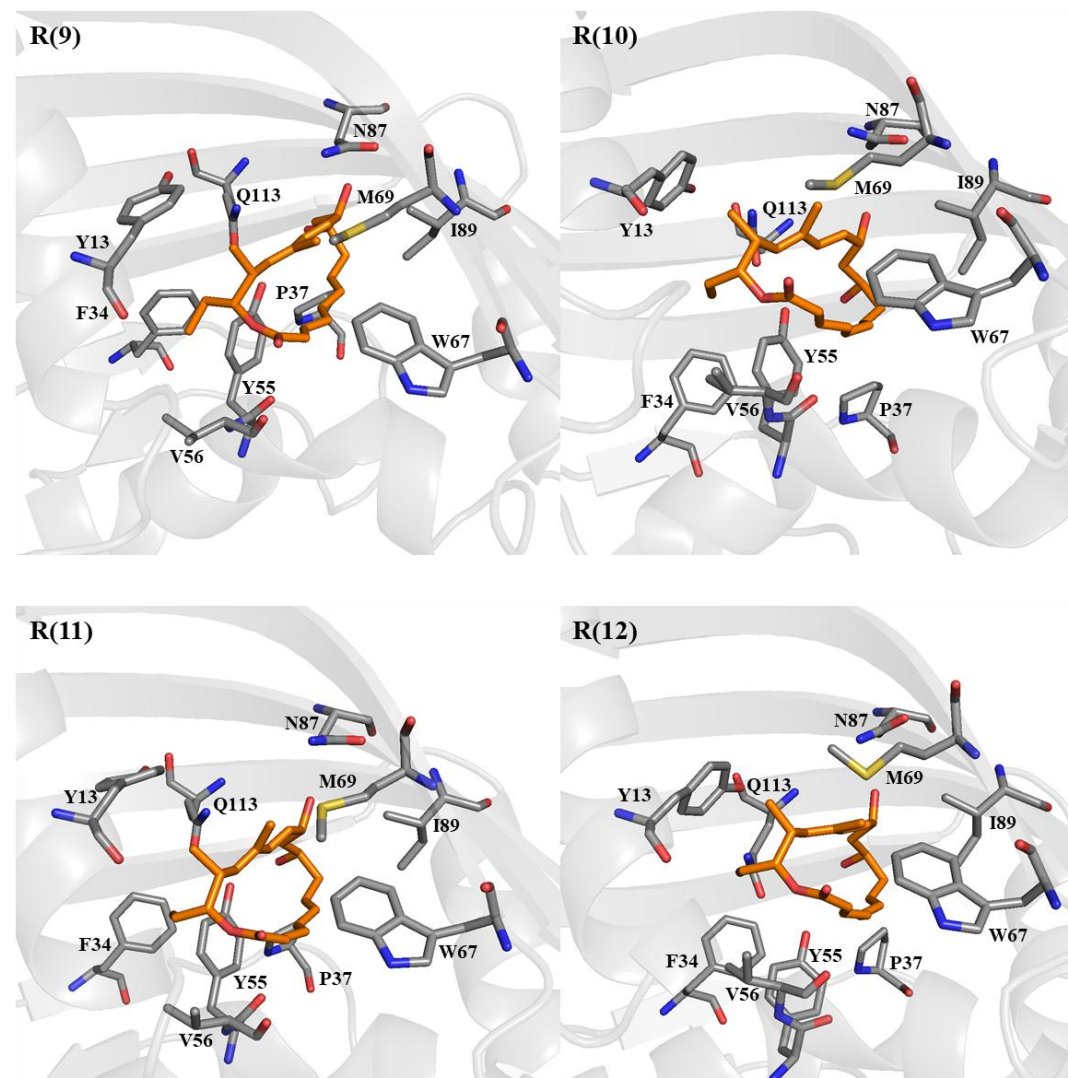

R(12)
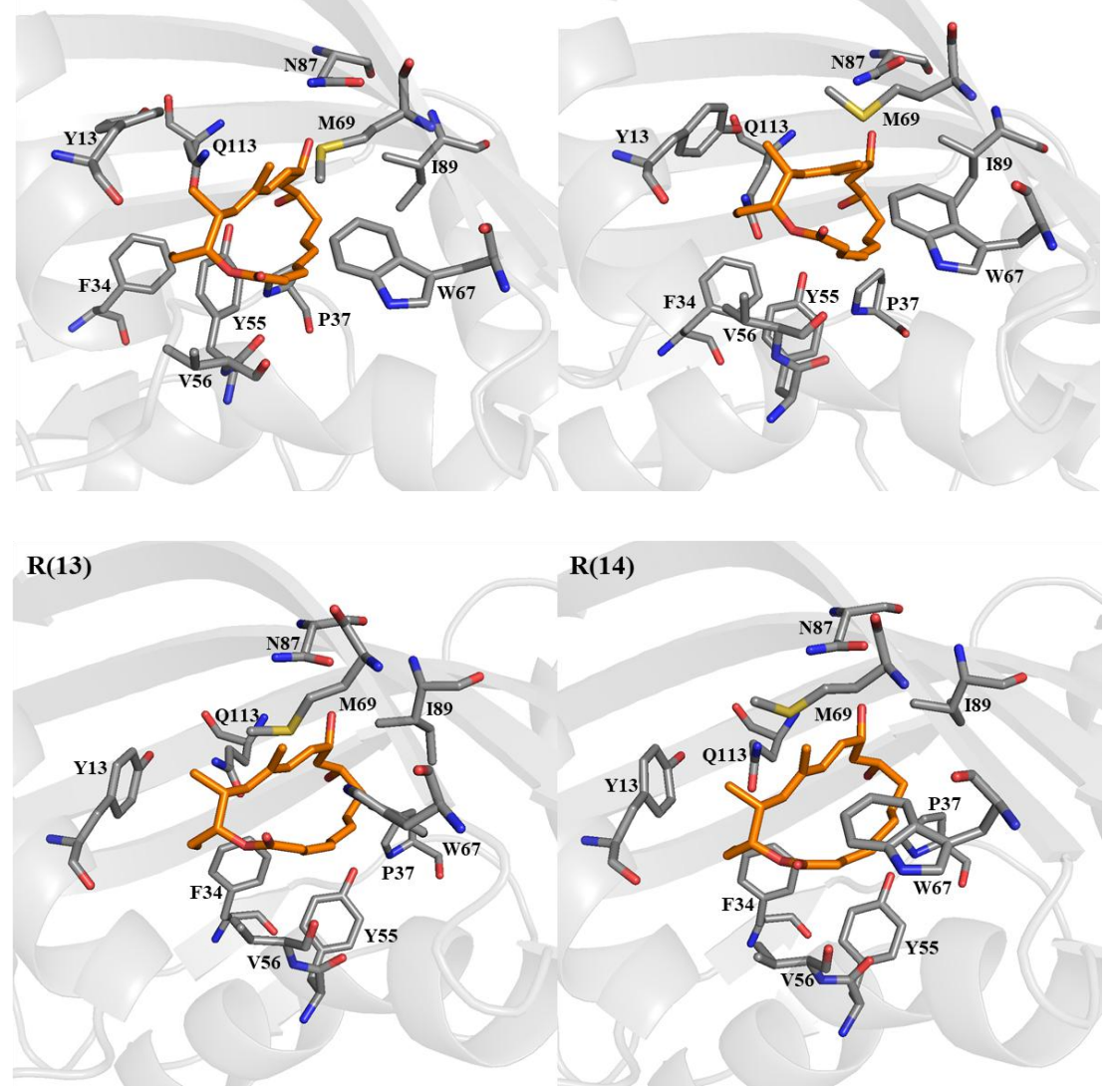

R(14)
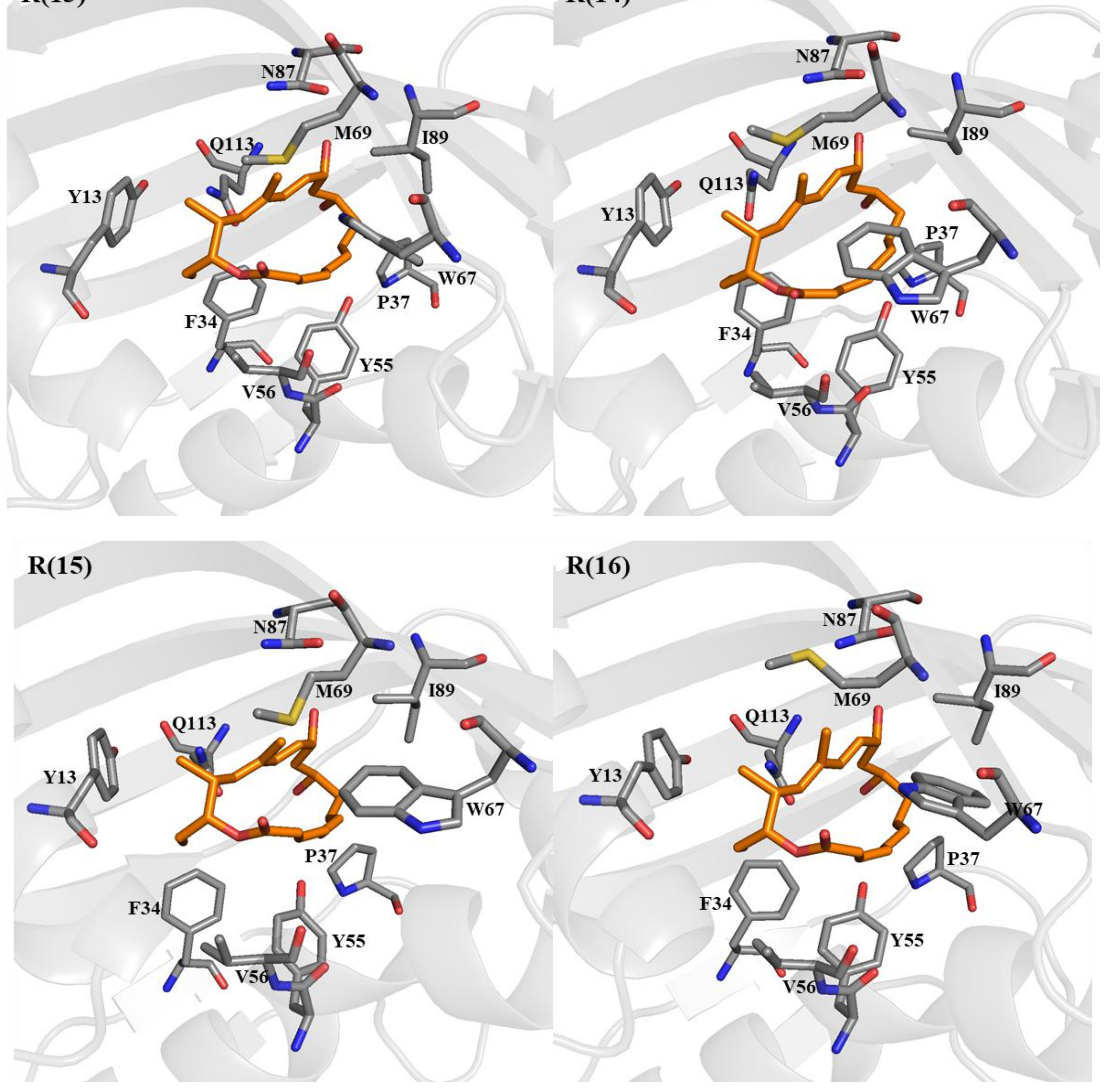

R(16)

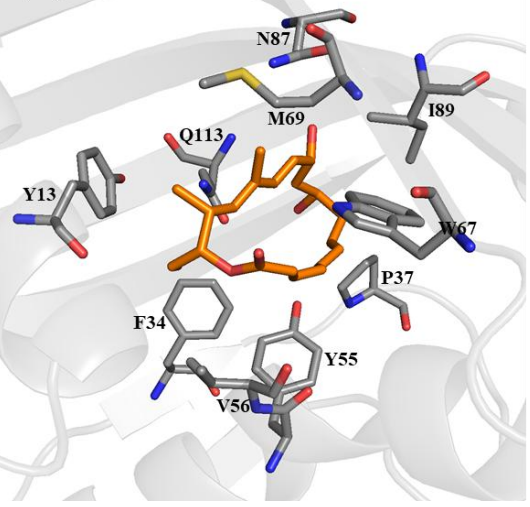



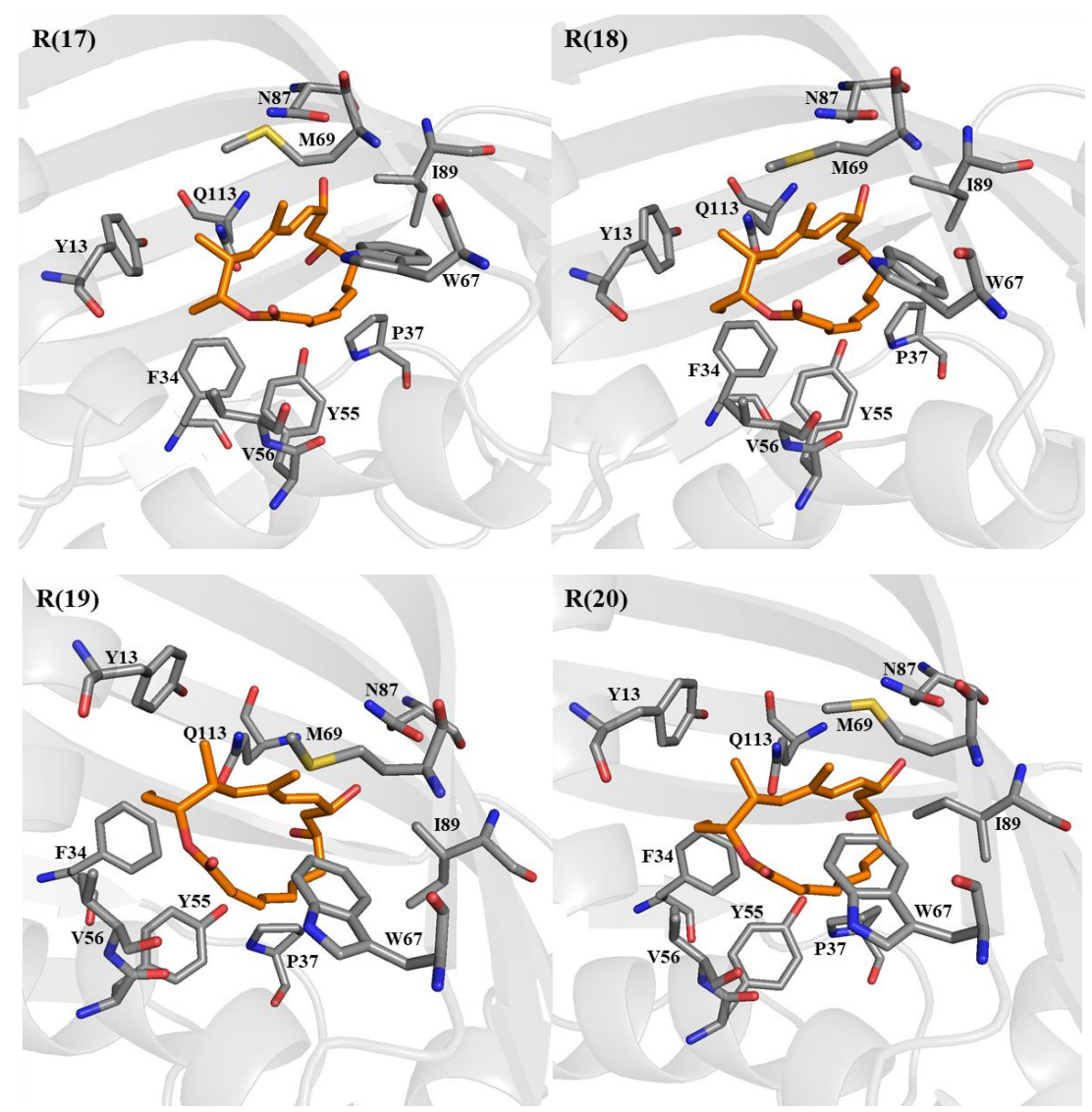

R(20)
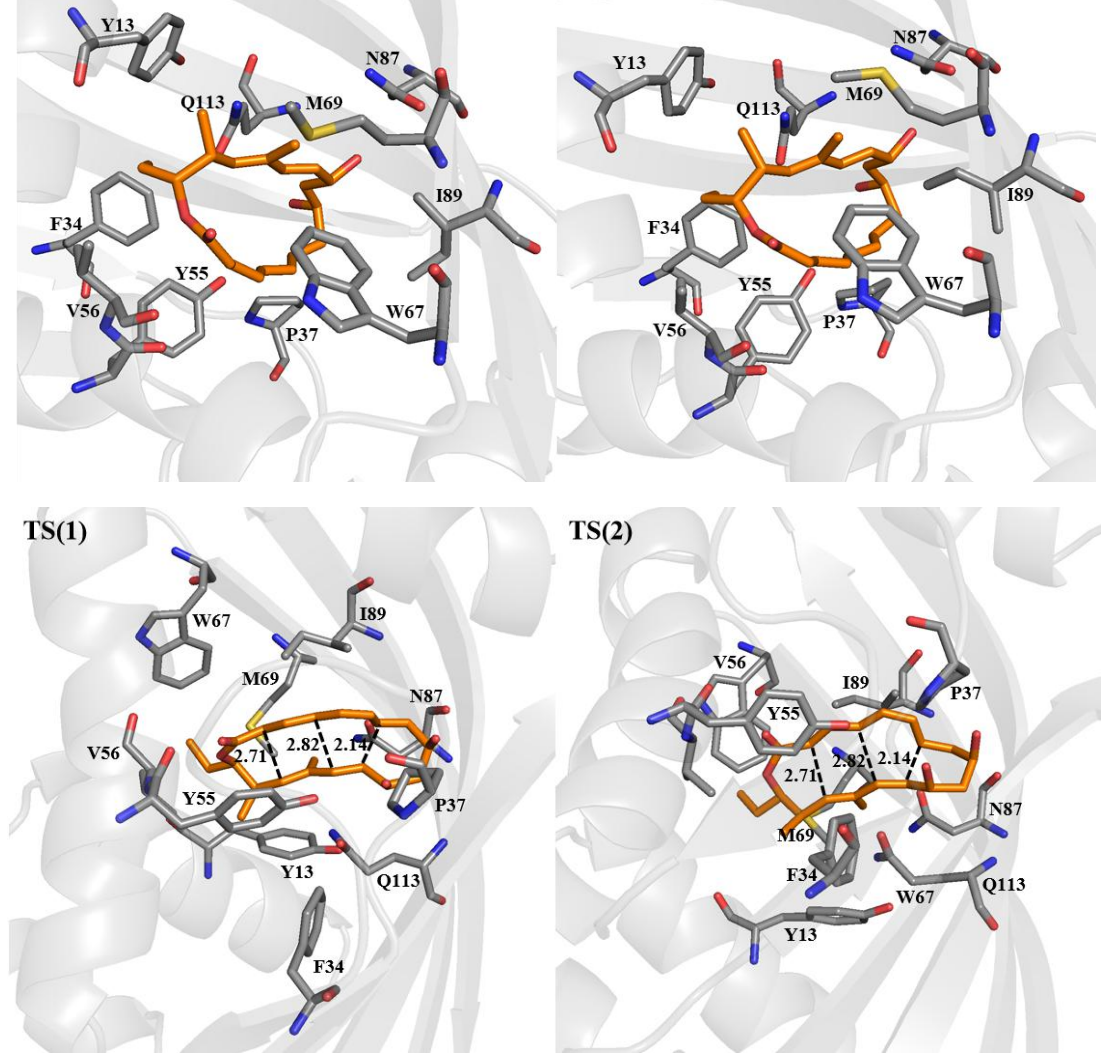

TS(3)
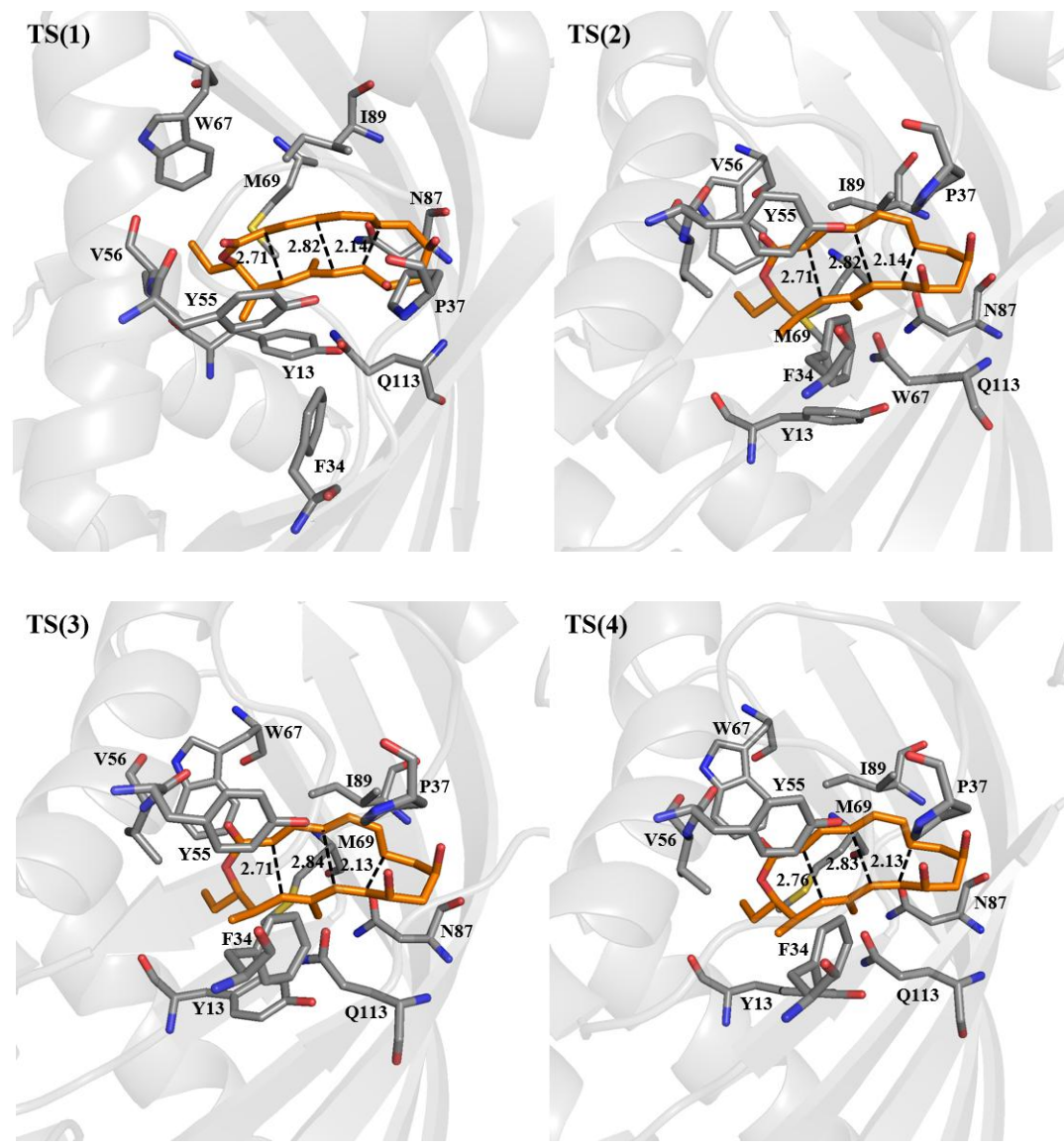

TS(4)

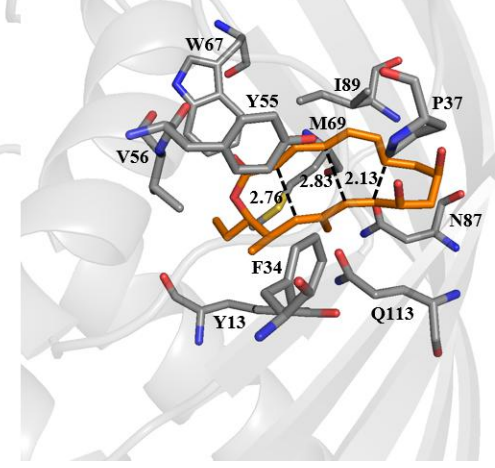



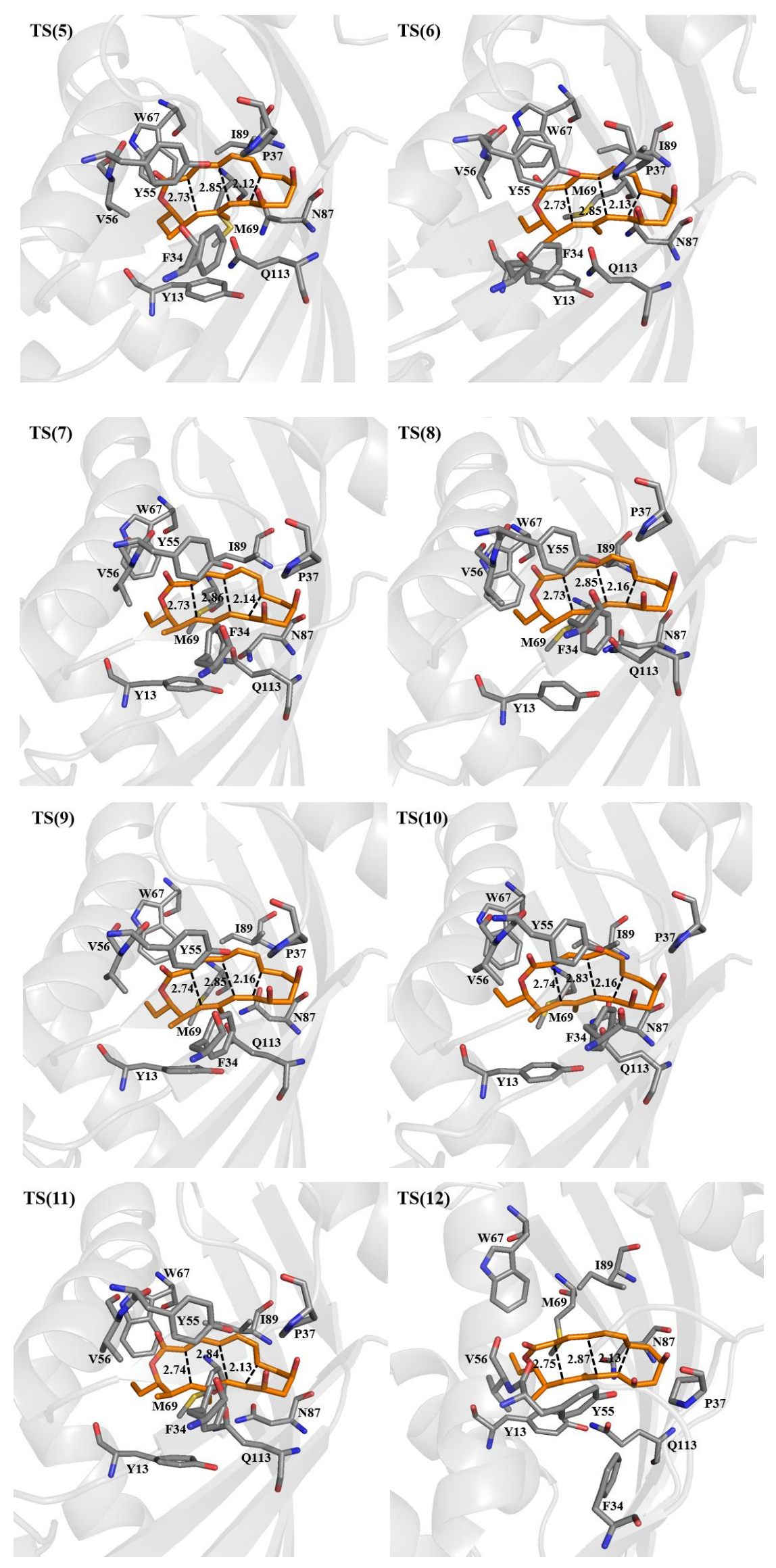


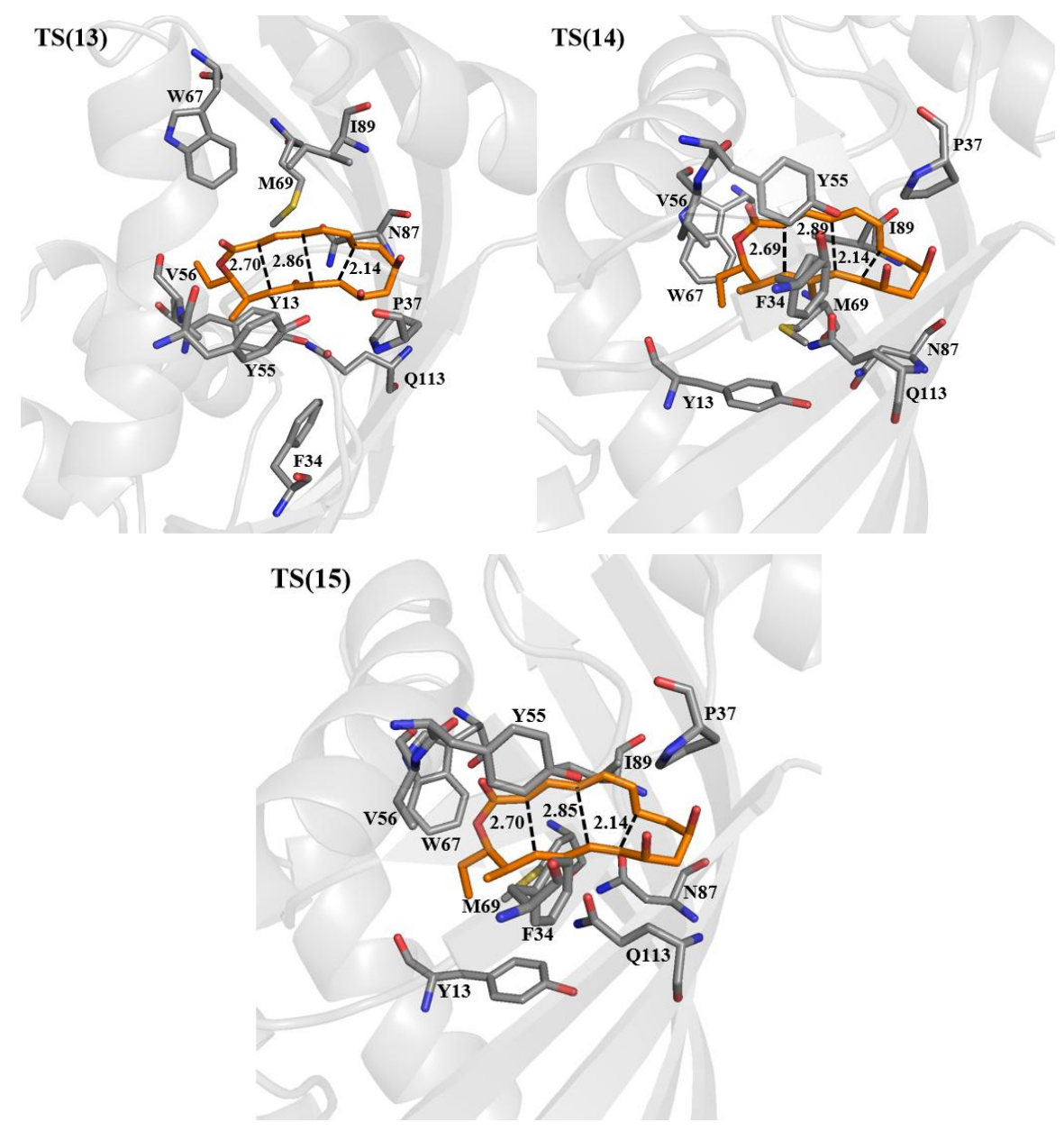

Figure S3. Cluster model was used to analyze the different results of reactants and transition states in enzyme during MD simulation. 

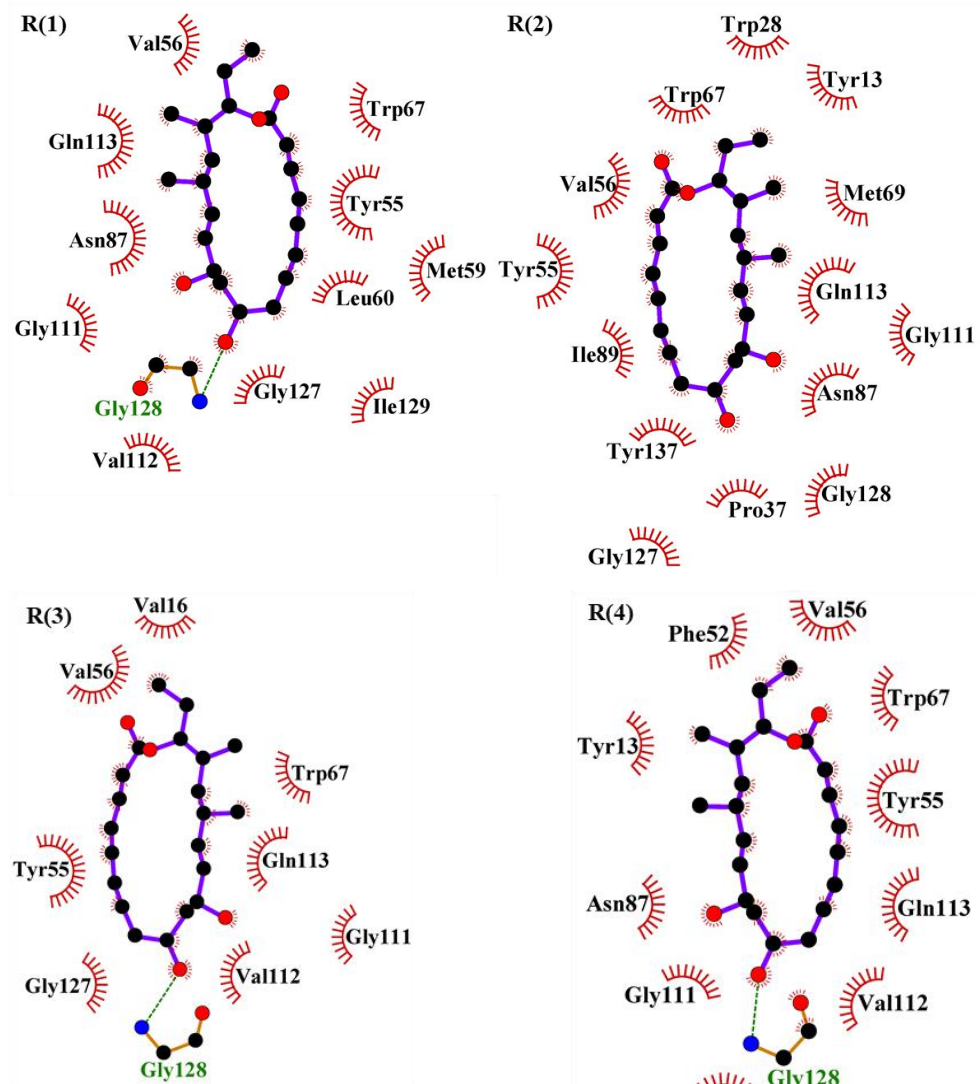

Gly127
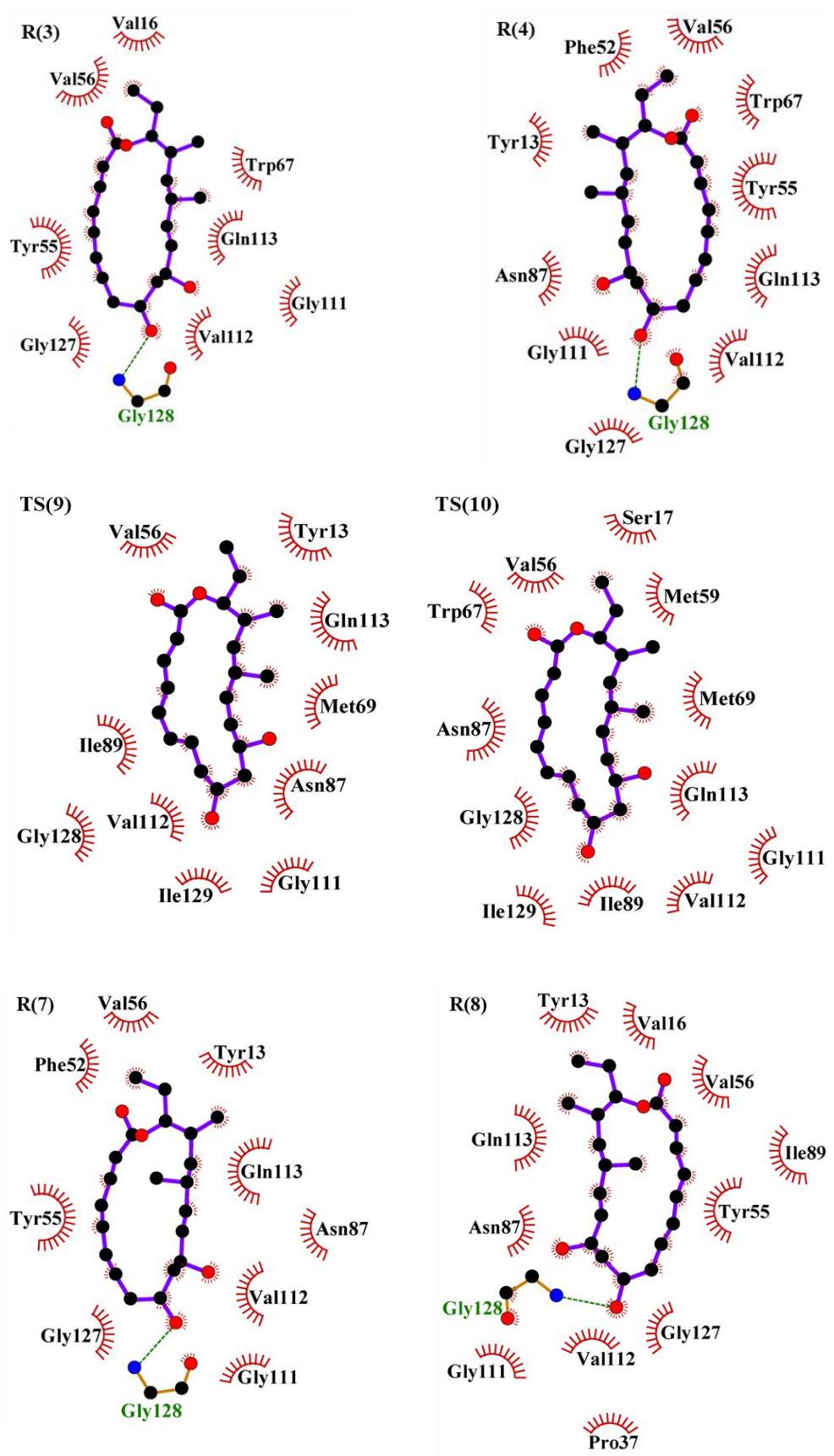

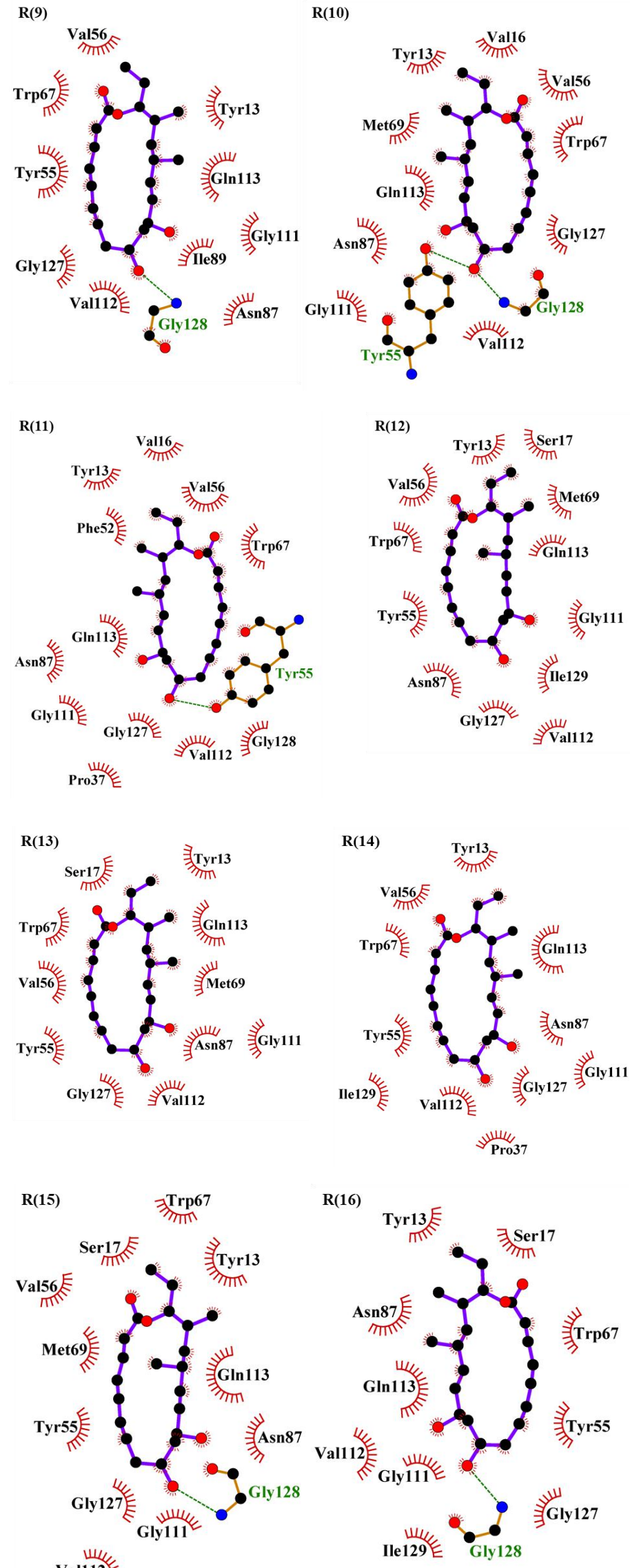

Val112 

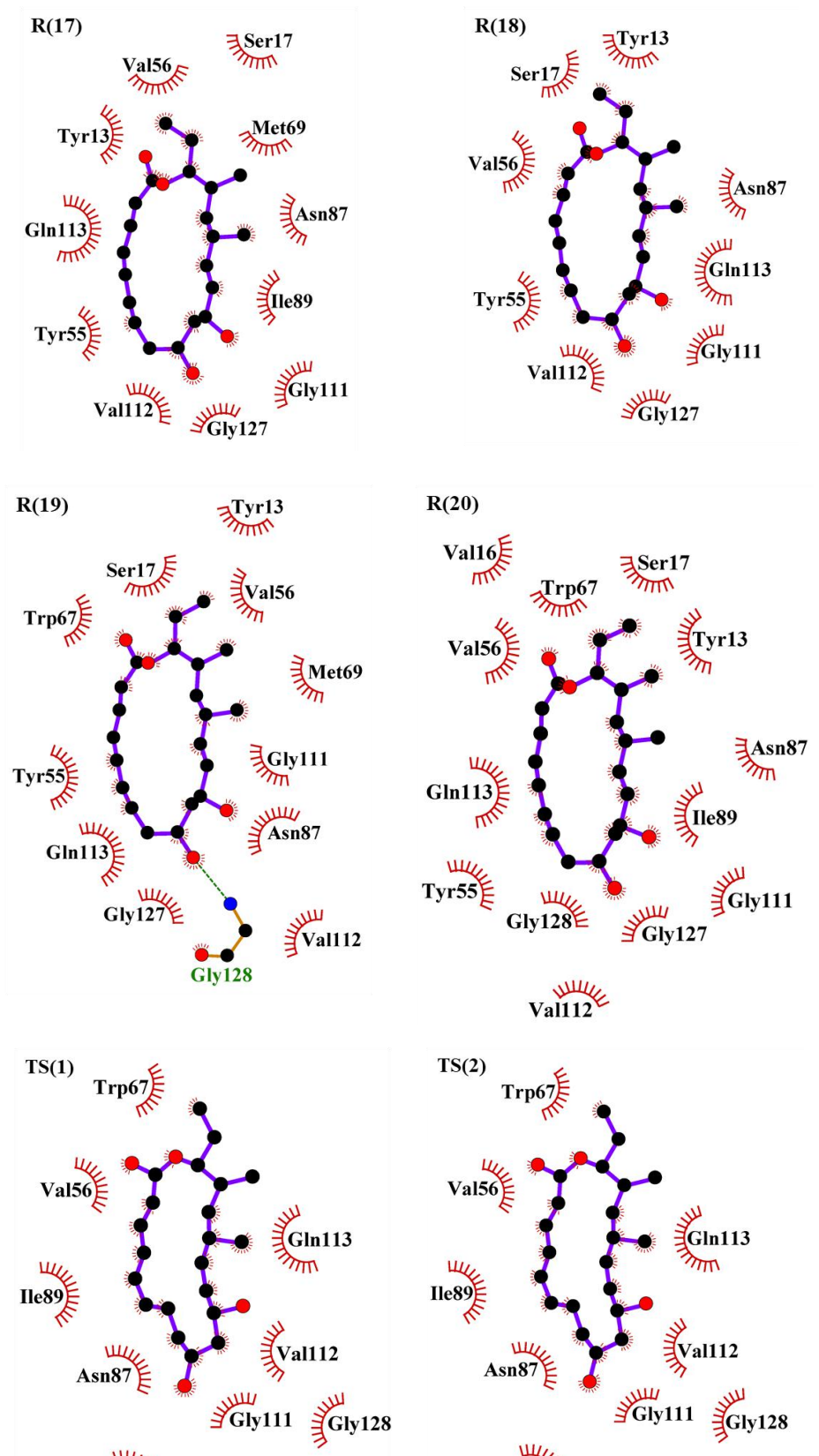
Ile129 Ile129
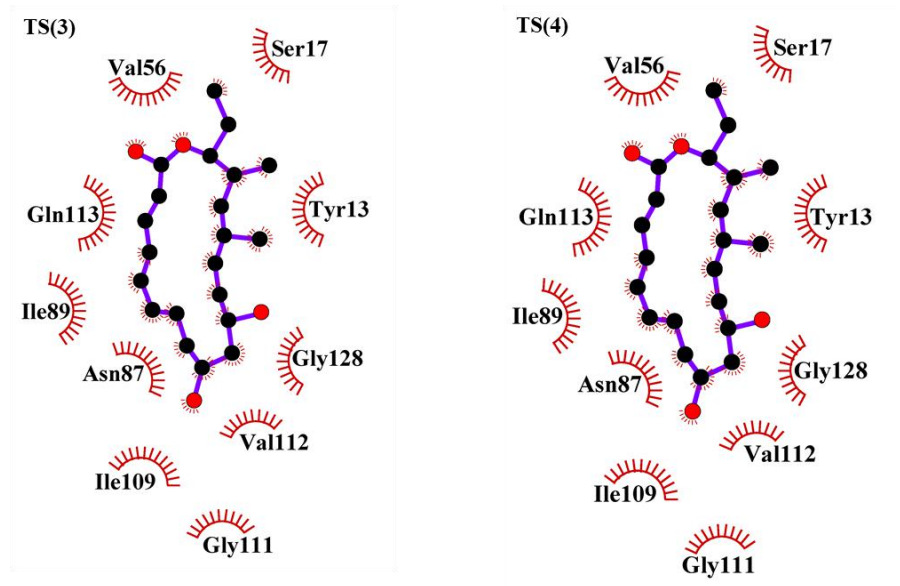


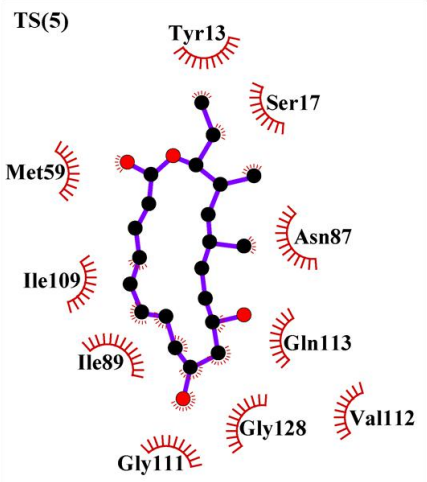

TS(6)

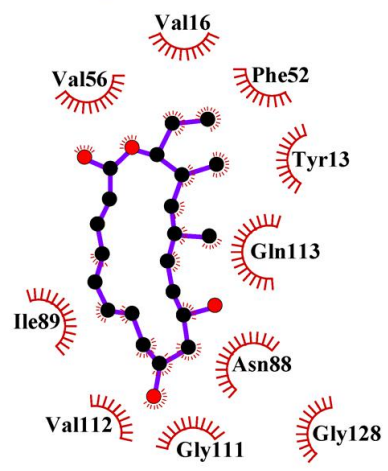

$$
\text { Ile129 }
$$

TS(7)

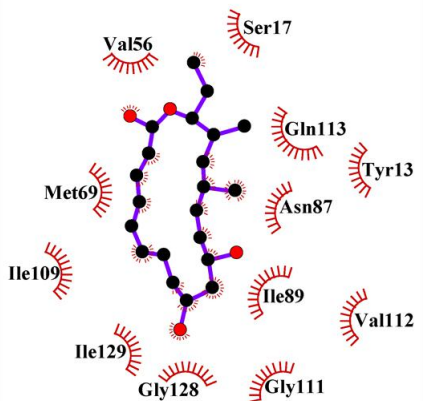

TS(8)

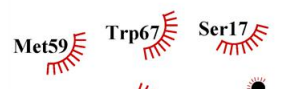
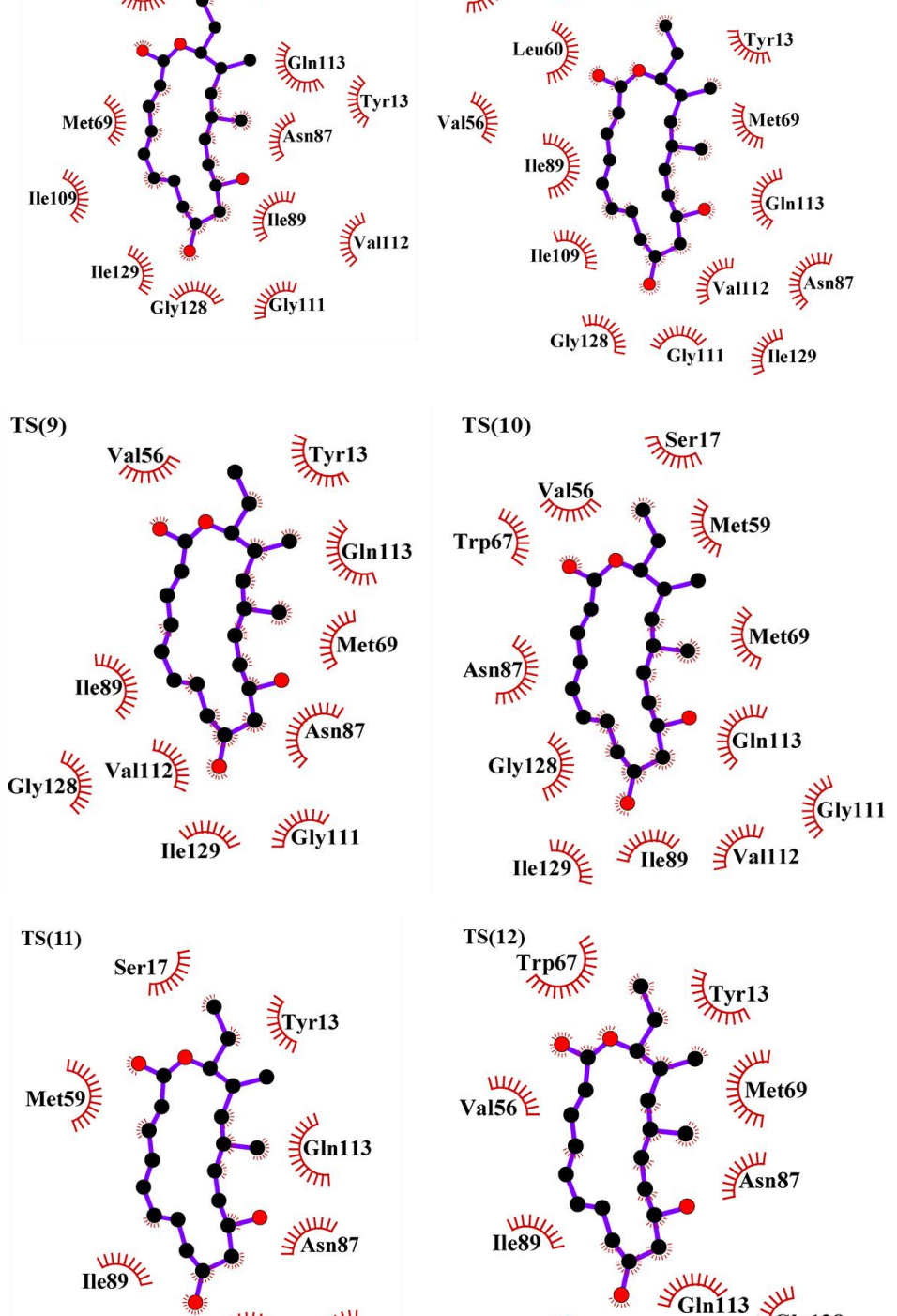

Ile129宸

垱Gly128 浔Val112 Gly111

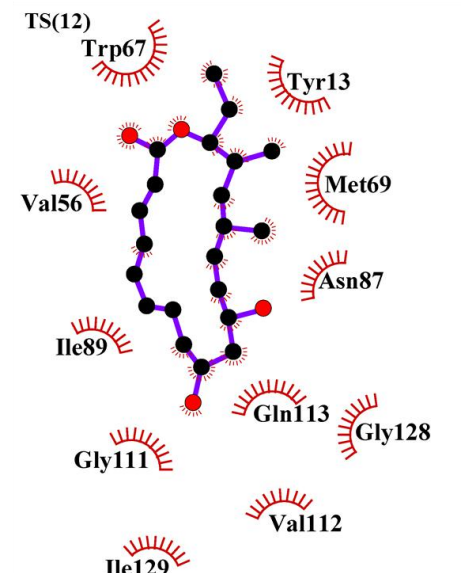




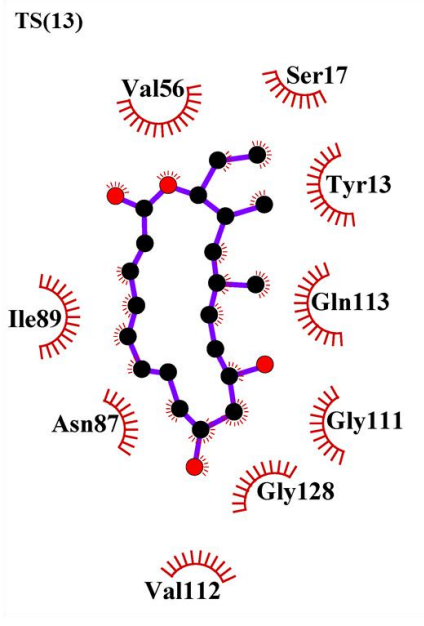

TS(14)
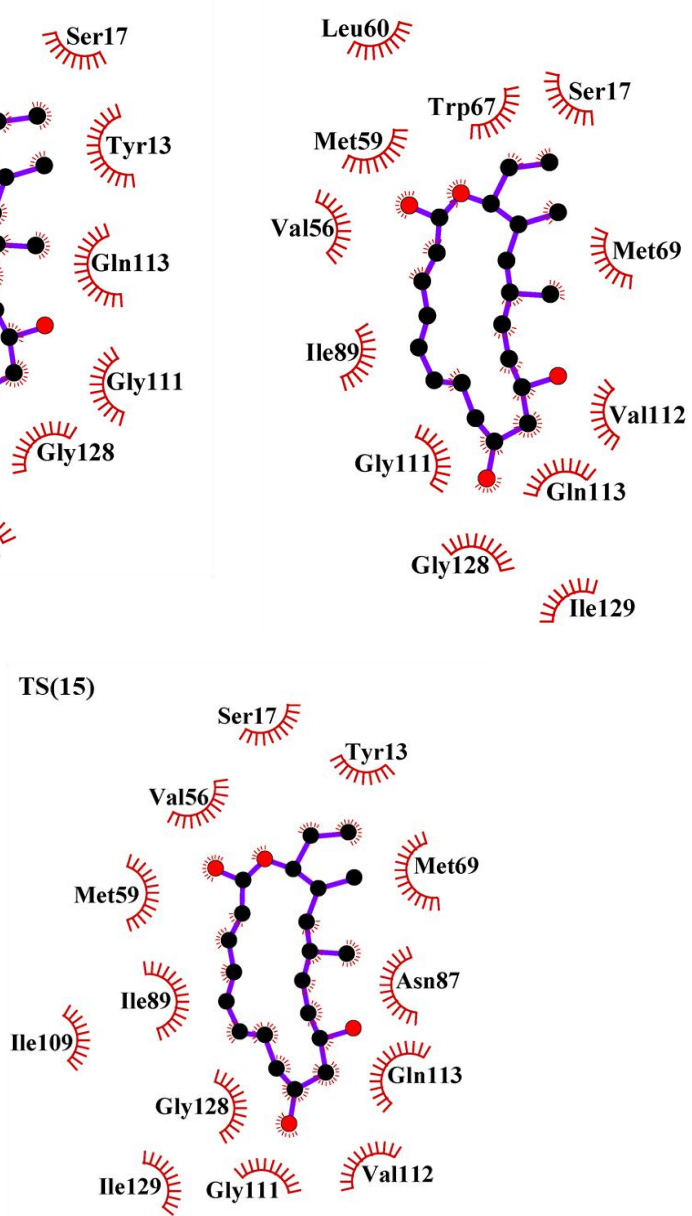

Figure S4. Interactions of reactants and transition states in enzyme during MD simulation as shown by the LigPlot ${ }^{+}$. 

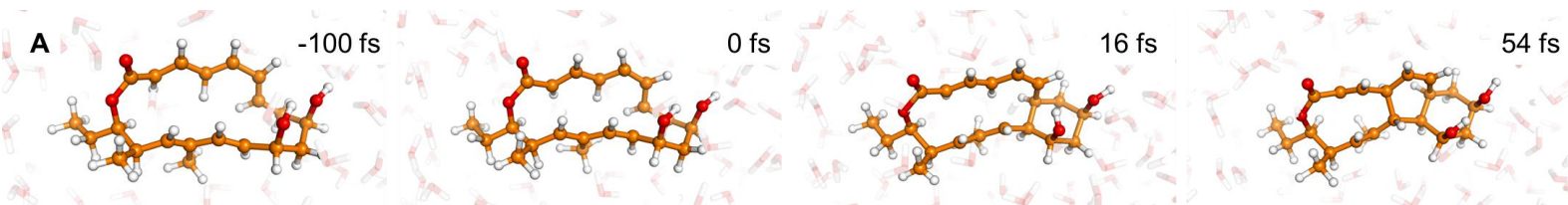

B
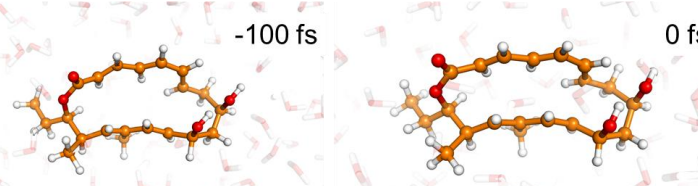

$0 \mathrm{fs}$
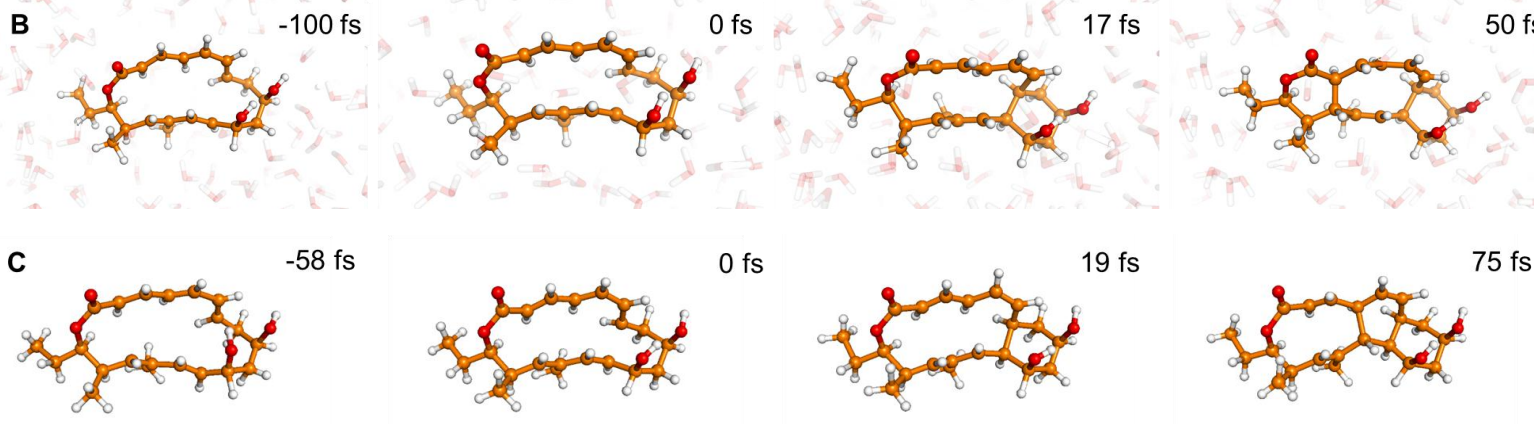

0 fs
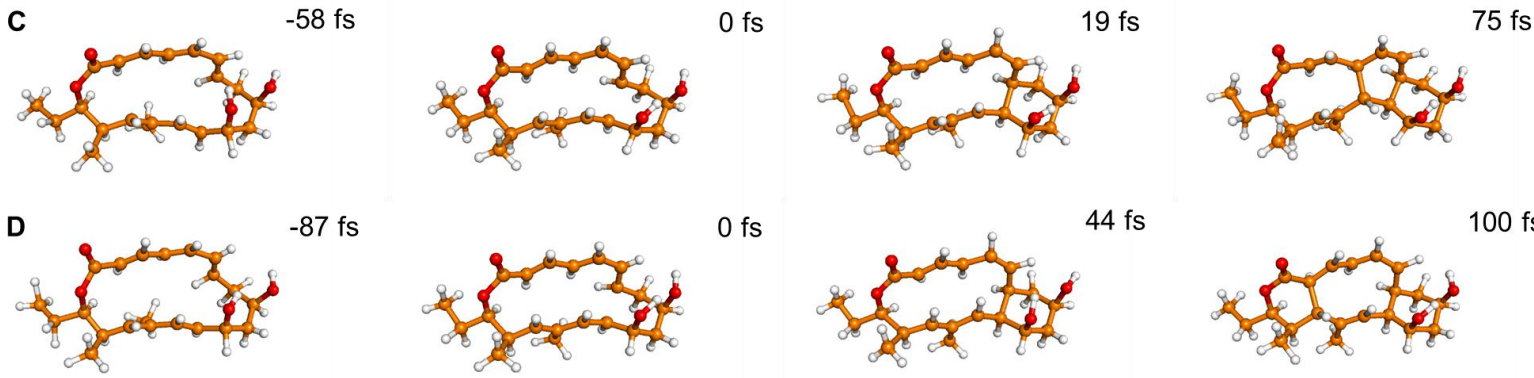

0 fs

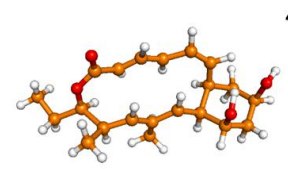

44 fs

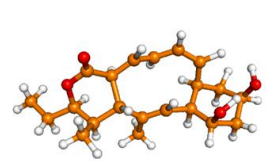

Figure S5. Typical trajectories for the formation of (A) [4+2] adduct in water, (B) [6+4] adduct in water, (C) [4+2] adduct in the gas phase, (D) [6+4] adduct in the gas phase. We define $1.6 \AA$ as the criterion for $\mathrm{C}-\mathrm{C}$ bond formation.

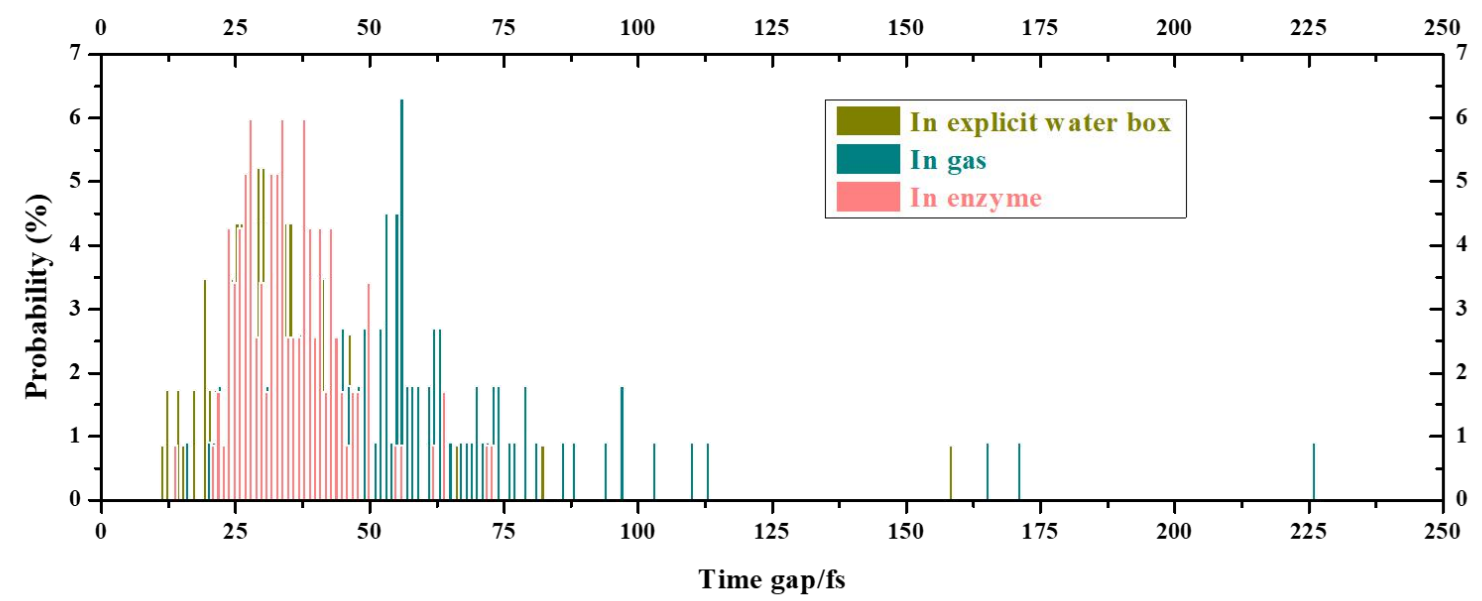

Figure S6. Distribution of time gaps for the $[6+4] /[4+2]$ cycloaddition in gas phase, water and enzyme environments. 


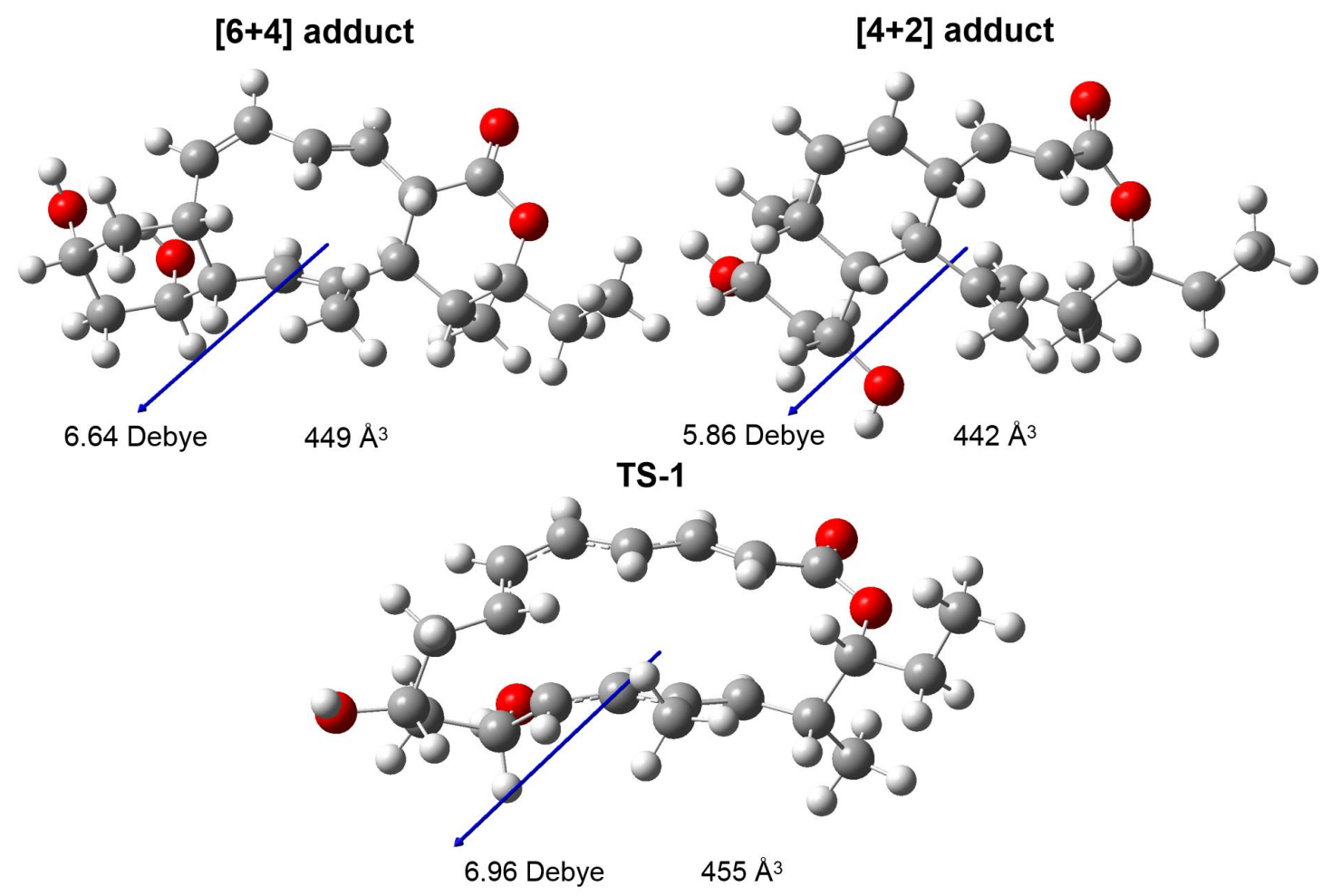

Figure S7. Computed dipole moments and molecular volumes of the $[6+4] /[4+2]$ adducts and TS-1.
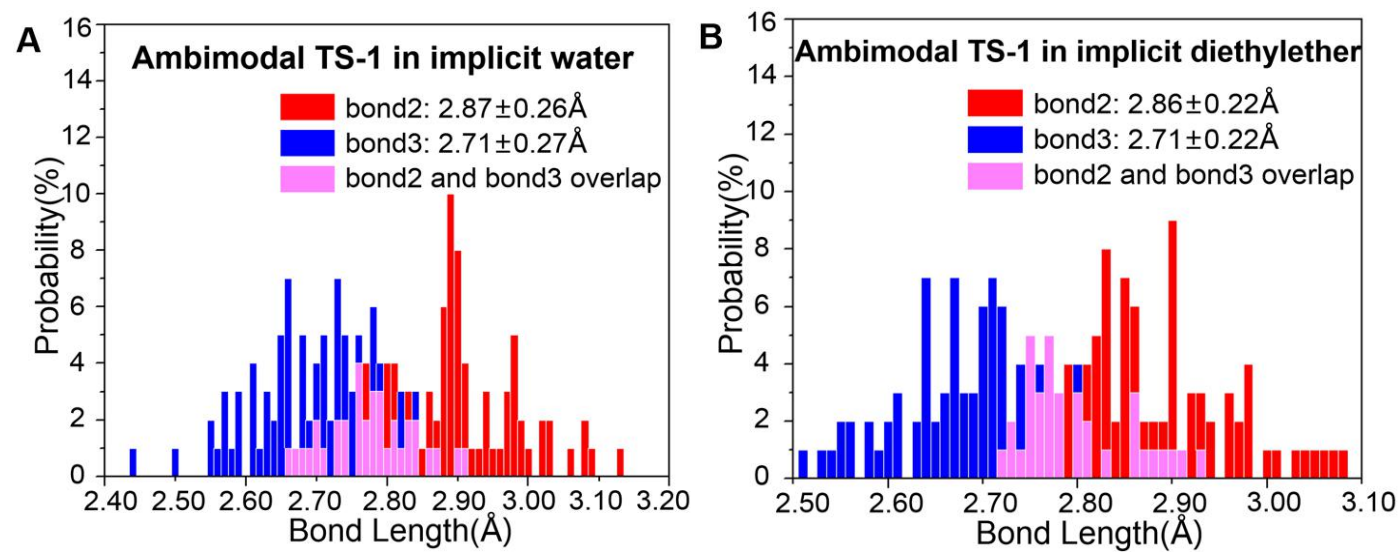

Figure S8. Distribution of bonds 2 and 3 in 100 TS geometries for (A) ambimodal TS-1 in implicit water and (B) ambimodal TS-1 in implicit diethylether. Bond 2 in red leads to the [4+2] adduct, while bond 3 in blue leads to the [6+4] adduct. 
Table S1. The energy of NgnD-TS and NgnD-R cluster for 10000 conformations from MD simulation.

\begin{tabular}{|c|c|c|c|c|c|c|c|c|}
\hline $\begin{array}{l}\text { TS_10000_ } \\
\text { conformation }\end{array}$ & Num. & & Hartree & & & & & $\begin{array}{l}\text { Oniom(QM/ } \\
\text { MM)_Success }\end{array}$ \\
\hline TSCluster: & 1 & average & -1119.192449 & stdev & 3.023043 & stderr & 0.733196 & 19 \\
\hline TSCluster: & 2 & average & -1119.188675 & stdev & 4.425111 & stderr & 1.142559 & 17 \\
\hline TSCluster: & 3 & average & -1119.192921 & stdev & 2.712799 & stderr & 0.904266 & 11 \\
\hline TSCluster: & 4 & average & -1119.191669 & stdev & 3.550815 & stderr & 1.025032 & 14 \\
\hline TSCluster: & 5 & average & -1119.194754 & stdev & 2.663616 & stderr & 0.738754 & 15 \\
\hline TSCluster: & 6 & average & -1119.190604 & stdev & 3.487037 & stderr & 0.93195 & 16 \\
\hline $\begin{array}{l}R_{-}{ }^{10000}- \\
\text { conformation }\end{array}$ & Num. & & & & & & & \\
\hline RCluster: & 1 & average & -1119.230004 & stdev & 5.161532 & stderr & 1.216585 & 20 \\
\hline RCluster: & 2 & average & -1119.227684 & stdev & 5.178803 & stderr & 1.256044 & 19 \\
\hline RCluster: & 3 & average & -1119.226484 & stdev & 3.084886 & stderr & 0.796514 & 17 \\
\hline RCluster: & 4 & average & -1119.21343 & stdev & 5.005676 & stderr & 1.251419 & 18 \\
\hline
\end{tabular}

Table S2. The calculated free energy barriers of reactant $(\mathbf{R})$ and transition state (TS-1) in enzyme and in water using QM/MM method.

\begin{tabular}{llll}
\hline Environment & $\mathbf{R}($ Hartree $)$ & TS-1(Hartree) & $\triangle \mathrm{G}(\mathrm{kcal} / \mathrm{mol})$ \\
\hline Enzyme & -1119.230004 & -1119.194754 & 22.1 \\
Water & -1118.872592 & -1118.834755 & 23.7 \\
\hline
\end{tabular}

Table S3. B3LYP-D3/6-31G(d)-computed molecular volumes for the $[6+4] /[4+2]$ adducts and TS-1.

\begin{tabular}{llll}
\hline & {$[6+4]$ adduct } & [4+2] adduct & TS-1 \\
\hline 1 & 269.6 & 265.8 & 273.9 \\
2 & 269.6 & 267.0 & 274.8 \\
3 & 272.1 & 267.3 & 273.6 \\
4 & 269.8 & 266.3 & 274.0 \\
5 & 270.5 & 265.3 & 273.8 \\
average $\mathrm{cm}^{3} / \mathrm{mol}$ & 270.3 & 266.3 & 274.0 \\
average $\AA^{3}$ & 449 & 442 & 455 \\
\hline
\end{tabular}


Table S4. Bacterial plasmids and strains.

\begin{tabular}{|c|c|c|}
\hline Plasmid/strain & Relevant characteristics & Reference \\
\hline \multicolumn{3}{|l|}{ Plasmid } \\
\hline pSET152-kasOp* & $\begin{array}{l}\text { pSET152 derived plasmid containing the promoter } \\
\text { kasOp* }\end{array}$ & 22 \\
\hline pYL02001 & $\begin{array}{l}\text { pSET152-kasOp* derived plasmid for } \\
\text { complementation of } n g n D \text { in strain } \operatorname{stm} A B C\end{array}$ & This study \\
\hline \multicolumn{3}{|l|}{ E. coli strains } \\
\hline $\mathrm{DH} 5 \alpha$ & General cloning host & 23 \\
\hline ET12567/pUZ8002 & $\begin{array}{l}\text { Methylation-deficient host used for } E \text {. } \\
\text { coli-Streptomyces intergeneric conjugation }\end{array}$ & 24 \\
\hline \multicolumn{3}{|c|}{ S. seoulensis strains } \\
\hline A01 & $\begin{array}{l}\text { Wild type strain for streptoseomycin (STM) } \\
\text { production }\end{array}$ & 6,20 \\
\hline stm $A B C$ & $\begin{array}{l}\text { Only containing genes } s t m A B C, \mathrm{STM} \text { non-producing, } \\
\text { used as netagive control }\end{array}$ & This study \\
\hline $\operatorname{stm} A B C: \because n g n D$ & $\begin{array}{l}\text { stm } A B C-n g n D, \text { complementation of gene } n g n D \text { to } \\
\text { strain stm } A B C, \text { STM non-producing }\end{array}$ & This study \\
\hline
\end{tabular}

Table S5. Primers used in this study.

\begin{tabular}{|c|c|c|}
\hline Oligonucleotide & Sequence $^{\mathrm{a}}$ & $\begin{array}{l}\text { Enzyme } \\
\text { sites }\end{array}$ \\
\hline \multicolumn{3}{|c|}{ for genes complementation $\left(5^{\prime}-3^{\prime}\right)$} \\
\hline 152-NgnD-F & $\begin{array}{l}\text { TGCTGCATGCATACGTACTAGT } \\
\text { GTCCTGGAAGCTCTGCGA }\end{array}$ & SpeI \\
\hline 152-NgnD-R & $\begin{array}{l}\text { CTATGACATGATTACGAATTCG } \\
\text { GCATTGTCCACGGTAGATT }\end{array}$ & EcoRI \\
\hline
\end{tabular}

${ }^{a}$ Letters highlighted in bold are sequences used for ligation independent cloning and the enzyme sites are indicated by underline. Lowercase letter indicated mutated nucleotide. 


\begin{tabular}{|c|c|c|c|}
\hline \multicolumn{4}{|c|}{$\begin{array}{l}\text { IV. B3LYP-D3/6-31G(d) calculated C } \\
\mathbf{1} \\
G_{\text {water }}=-1118.553272 \text { Hartree }\end{array}$} \\
\hline $\mathrm{C}$ & -4.838327 & 0.340397 & 2.574520 \\
\hline $\mathrm{C}$ & -4.045270 & -0.717842 & 1.801237 \\
\hline $\mathrm{C}$ & -3.893228 & -0.373560 & 0.321884 \\
\hline $\mathrm{C}$ & -3.155840 & -1.427967 & -0.549512 \\
\hline $\mathrm{C}$ & -1.734781 & -1.680686 & -0.110544 \\
\hline $\mathrm{C}$ & -0.585285 & -1.339447 & -0.735490 \\
\hline $\mathrm{C}$ & 0.690352 & -1.783993 & -0.154947 \\
\hline $\mathrm{C}$ & 1.918221 & -1.588625 & -0.668248 \\
\hline $\mathrm{C}$ & 3.597022 & 1.929025 & 1.109610 \\
\hline $\mathrm{C}$ & 2.725743 & 2.608134 & 0.334959 \\
\hline $\mathrm{C}$ & 1.316817 & 2.644578 & 0.639154 \\
\hline $\mathrm{C}$ & 0.332314 & 2.978962 & -0.233999 \\
\hline $\mathrm{C}$ & -1.004587 & 2.486189 & -0.037564 \\
\hline $\mathrm{C}$ & -1.994173 & 2.490638 & -0.959209 \\
\hline $\mathrm{C}$ & -3.145902 & 1.579917 & -0.870997 \\
\hline $\mathrm{C}$ & -3.945880 & -2.750857 & -0.598032 \\
\hline $\mathrm{C}$ & 3.195945 & -2.112719 & -0.042304 \\
\hline $\mathrm{C}$ & 3.963506 & -1.029221 & 0.734162 \\
\hline $\mathrm{C}$ & 4.602454 & 0.045335 & -0.149454 \\
\hline $\mathrm{C}$ & 4.897467 & 1.368818 & 0.619655 \\
\hline $\mathrm{C}$ & -0.517703 & -0.544982 & -2.018510 \\
\hline $\mathrm{O}$ & -3.951007 & 1.409273 & -1.770405 \\
\hline $\mathrm{O}$ & -3.146293 & 0.865360 & 0.286128 \\
\hline $\mathrm{O}$ & 2.952035 & -3.150041 & 0.908349 \\
\hline $\mathrm{O}$ & 5.793003 & -0.529045 & -0.683678 \\
\hline $\mathrm{H}$ & -4.343644 & 1.314521 & 2.515243 \\
\hline $\mathrm{H}$ & -4.933641 & 0.066545 & 3.630924 \\
\hline $\mathrm{H}$ & -5.848847 & 0.452113 & 2.162697 \\
\hline $\mathrm{H}$ & -3.047120 & -0.834391 & 2.241062 \\
\hline $\mathrm{H}$ & -4.546816 & -1.689202 & 1.882139 \\
\hline $\mathrm{H}$ & -4.877548 & -0.193716 & -0.126755 \\
\hline $\mathrm{H}$ & -3.163732 & -1.013569 & -1.560944 \\
\hline $\mathrm{H}$ & -1.642943 & -2.253284 & 0.814440 \\
\hline $\mathrm{H}$ & 0.618266 & -2.347839 & 0.775192 \\
\hline $\mathrm{H}$ & 2.045538 & -1.028818 & -1.592556 \\
\hline $\mathrm{H}$ & 3.247344 & 1.570755 & 2.077318 \\
\hline $\mathrm{H}$ & 3.042175 & 2.975531 & -0.642481 \\
\hline $\mathrm{H}$ & 1.023579 & 2.180881 & 1.581915 \\
\hline $\mathrm{H}$ & 0.579132 & 3.445880 & -1.187267 \\
\hline
\end{tabular}




$\begin{array}{rrrr}\mathrm{H} & -1.173760 & 1.917417 & 0.873572 \\ \mathrm{H} & -1.907248 & 3.020897 & -1.903069 \\ \mathrm{H} & -3.914840 & -3.279096 & 0.361707 \\ \mathrm{H} & -3.519878 & -3.417027 & -1.355139 \\ \mathrm{H} & -4.997222 & -2.572677 & -0.854315 \\ \mathrm{H} & 3.855393 & -2.480512 & -0.846806 \\ \mathrm{H} & 4.763564 & -1.516138 & 1.303708 \\ \mathrm{H} & 3.265068 & -0.586863 & 1.449472 \\ \mathrm{H} & 3.909277 & 0.310952 & -0.964069 \\ \mathrm{H} & 5.392667 & 2.061762 & -0.074690 \\ \mathrm{H} & 5.595597 & 1.155938 & 1.436947 \\ \mathrm{H} & 0.081657 & 0.360890 & -1.868230 \\ \mathrm{H} & -0.031281 & -1.128969 & -2.810509 \\ \mathrm{H} & -1.497722 & -0.231239 & -2.380316 \\ \mathrm{H} & 2.429883 & -3.832659 & 0.457052 \\ \mathrm{H} & 6.142018 & 0.074965 & -1.357615\end{array}$

$\begin{array}{lccc}\mathbf{2} & & & \\ G_{\text {water }}= & -1118.583634 & \text { Hartree } & \\ ---- & - & \\ \mathrm{C} & 6.245788 & -0.829626 & 1.306347 \\ \mathrm{C} & 5.218194 & -1.403899 & 0.326158 \\ \mathrm{C} & 3.912978 & -0.614137 & 0.316659 \\ \mathrm{C} & 2.769749 & -1.215527 & -0.518809 \\ \mathrm{C} & 1.516632 & -0.282396 & -0.466468 \\ \mathrm{C} & 0.289124 & -0.865113 & 0.212368 \\ \mathrm{C} & -0.913717 & -0.669209 & -0.357368 \\ \mathrm{C} & -2.280709 & -0.912494 & 0.222192 \\ \mathrm{C} & -2.829901 & 0.340727 & 1.018027 \\ \mathrm{C} & -2.785650 & 1.670281 & 0.281151 \\ \mathrm{C} & -1.693012 & 2.441890 & 0.124438 \\ \mathrm{C} & -0.373955 & 2.023884 & 0.587178 \\ \mathrm{C} & 0.770928 & 2.106516 & -0.107654 \\ \mathrm{C} & 1.879585 & 1.143103 & 0.179477 \\ \mathrm{C} & 3.231525 & 1.602004 & -0.339476 \\ \mathrm{C} & 3.179885 & -1.481370 & -1.975110 \\ \mathrm{C} & -3.272094 & -1.381744 & -0.872188 \\ \mathrm{C} & -4.645207 & -1.705679 & -0.261910 \\ \mathrm{C} & -5.231544 & -0.526680 & 0.518284 \\ \mathrm{C} & -4.241204 & 0.012999 & 1.561406 \\ \mathrm{C} & 0.474875 & -1.435383 & 1.597929 \\ \mathrm{O} & 3.450885 & 2.669882 & -0.859672 \\ \mathrm{O} & 4.241197 & 0.703125 & -0.192773\end{array}$




$\begin{array}{lrrr}\mathrm{O} & -3.373097 & -0.453098 & -1.945214 \\ \mathrm{O} & -5.591271 & 0.465745 & -0.467437 \\ \mathrm{H} & 6.476940 & 0.209283 & 1.052530 \\ \mathrm{H} & 7.177179 & -1.405220 & 1.281209 \\ \mathrm{H} & 5.865712 & -0.850219 & 2.335452 \\ \mathrm{H} & 5.635422 & -1.409464 & -0.686538 \\ \mathrm{H} & 4.983337 & -2.445282 & 0.584274 \\ \mathrm{H} & 3.571358 & -0.506827 & 1.357517 \\ \mathrm{H} & 2.522835 & -2.178745 & -0.056601 \\ \mathrm{H} & 1.237619 & -0.048354 & -1.499026 \\ \mathrm{H} & -0.945711 & -0.185669 & -1.331299 \\ \mathrm{H} & -2.236600 & -1.723916 & 0.963511 \\ \mathrm{H} & -2.172193 & 0.427812 & 1.892082 \\ \mathrm{H} & -3.710974 & 2.000326 & -0.180372 \\ \mathrm{H} & -1.763670 & 3.343671 & -0.482493 \\ \mathrm{H} & -0.365085 & 1.415260 & 1.489925 \\ \mathrm{H} & 0.834500 & 2.665781 & -1.038385 \\ \mathrm{H} & 1.984018 & 0.993895 & 1.262774 \\ \mathrm{H} & 3.523248 & -0.560193 & -2.458703 \\ \mathrm{H} & 2.323817 & -1.863844 & -2.541306 \\ \mathrm{H} & 3.983683 & -2.221030 & -2.045549 \\ \mathrm{H} & -2.861659 & -2.297828 & -1.316150 \\ \mathrm{H} & -4.548778 & -2.559593 & 0.420750 \\ \mathrm{H} & -5.339768 & -1.992138 & -1.058933 \\ \mathrm{H} & -6.146258 & -0.854249 & 1.036264 \\ \mathrm{H} & -4.150333 & -0.753603 & 2.343394 \\ \mathrm{H} & -4.668372 & 0.899502 & 2.051595 \\ \mathrm{H} & -0.453303 & -1.837479 & 2.010945 \\ \mathrm{H} & 0.835045 & -0.666691 & 2.297757 \\ \mathrm{H} & 1.218659 & -2.241373 & 1.616592 \\ \mathrm{H} & -4.050223 & 0.198918 & -1.693124 \\ \mathrm{H} & -5.915759 & 1.253146 & -0.003114\end{array}$

\begin{tabular}{|c|c|c|c|}
\hline \multicolumn{4}{|c|}{$\begin{array}{l}3 \\
G_{\text {water }}=-1118.579852 \text { Hartree }\end{array}$} \\
\hline $\mathrm{O}$ & 1.964748 & -2.324614 & -1.500148 \\
\hline $\mathrm{O}$ & 4.538944 & -1.109038 & 2.398866 \\
\hline $\mathrm{O}$ & -2.901642 & 2.324491 & 1.935865 \\
\hline $\mathrm{C}$ & 2.892810 & -1.398307 & -0.945877 \\
\hline $\mathrm{C}$ & 3.229219 & -1.720605 & 0.513434 \\
\hline $\mathrm{C}$ & 4.311514 & -0.777245 & 1.031465 \\
\hline $\mathrm{C}$ & 3.874892 & 0.680977 & 0.860433 \\
\hline
\end{tabular}




\begin{tabular}{|c|c|c|c|}
\hline $\mathrm{C}$ & 3.442051 & 1.015131 & -0.590859 \\
\hline $\mathrm{C}$ & 2.988213 & 2.447847 & -0.672911 \\
\hline $\mathrm{C}$ & 1.707539 & 2.807003 & -0.770367 \\
\hline $\mathrm{C}$ & 0.554321 & 1.836124 & -0.825480 \\
\hline $\mathrm{C}$ & 0.992033 & 0.344132 & -0.456093 \\
\hline $\mathrm{C}$ & 2.357309 & 0.037807 & -1.122700 \\
\hline $\mathrm{C}$ & -0.563314 & 2.190793 & 0.114250 \\
\hline $\mathrm{C}$ & -1.827736 & 1.832468 & -0.140816 \\
\hline $\mathrm{C}$ & -2.791750 & 1.614050 & 0.962196 \\
\hline $\mathrm{C}$ & -0.168077 & -0.598494 & -0.737161 \\
\hline $\mathrm{C}$ & -0.529172 & -0.873740 & -2.176923 \\
\hline $\mathrm{C}$ & -0.955480 & -0.947781 & 0.294838 \\
\hline $\mathrm{C}$ & -2.318652 & -1.604686 & 0.262470 \\
\hline $\mathrm{C}$ & -2.601832 & -2.316526 & 1.594611 \\
\hline $\mathrm{C}$ & -3.427538 & -0.571637 & -0.102976 \\
\hline $\mathrm{C}$ & -4.828223 & -1.175578 & -0.221210 \\
\hline $\mathrm{C}$ & -5.847330 & -0.184275 & -0.790114 \\
\hline $\mathrm{O}$ & -3.549441 & 0.474104 & 0.898778 \\
\hline $\mathrm{H}$ & 2.255356 & -3.216736 & -1.256219 \\
\hline $\mathrm{H}$ & 5.216111 & -0.504608 & 2.741411 \\
\hline $\mathrm{H}$ & 3.833621 & -1.445343 & -1.525522 \\
\hline $\mathrm{H}$ & 2.333005 & -1.633211 & 1.138037 \\
\hline $\mathrm{H}$ & 3.584992 & -2.756259 & 0.599911 \\
\hline $\mathrm{H}$ & 5.231159 & -0.944839 & 0.441497 \\
\hline $\mathrm{H}$ & 4.690438 & 1.355093 & 1.159021 \\
\hline $\mathrm{H}$ & 3.046350 & 0.869367 & 1.552851 \\
\hline $\mathrm{H}$ & 4.330855 & 0.897255 & -1.230081 \\
\hline $\mathrm{H}$ & 3.762350 & 3.212325 & -0.618083 \\
\hline $\mathrm{H}$ & 1.442769 & 3.862422 & -0.818527 \\
\hline $\mathrm{H}$ & 0.162592 & 1.821975 & -1.853509 \\
\hline $\mathrm{H}$ & 1.146458 & 0.345889 & 0.628517 \\
\hline $\mathrm{H}$ & 2.255401 & 0.212145 & -2.201976 \\
\hline $\mathrm{H}$ & -0.290801 & 2.499733 & 1.122895 \\
\hline $\mathrm{H}$ & -2.084789 & 1.476937 & -1.132529 \\
\hline $\mathrm{H}$ & -1.001606 & 0.003548 & -2.643403 \\
\hline $\mathrm{H}$ & -1.234390 & -1.704851 & -2.266280 \\
\hline $\mathrm{H}$ & 0.352307 & -1.128564 & -2.767887 \\
\hline $\mathrm{H}$ & -0.641600 & -0.636037 & 1.291741 \\
\hline $\mathrm{H}$ & -2.350746 & -2.346751 & -0.547734 \\
\hline $\mathrm{H}$ & -2.701031 & -1.583598 & 2.402731 \\
\hline $\mathrm{H}$ & -3.522017 & -2.907383 & 1.557223 \\
\hline $\mathrm{H}$ & -1.777551 & -2.992845 & 1.845020 \\
\hline $\mathrm{H}$ & -3.167595 & -0.131004 & -1.071114 \\
\hline
\end{tabular}




$\begin{array}{lrrr}\mathrm{H} & -5.153453 & -1.512211 & 0.769087 \\ \mathrm{H} & -4.764510 & -2.066184 & -0.860514 \\ \mathrm{H} & -5.561548 & 0.143442 & -1.797831 \\ \mathrm{H} & -6.843051 & -0.635990 & -0.855022 \\ \mathrm{H} & -5.914726 & 0.701990 & -0.151861\end{array}$

\section{TS-1}

$G_{\text {water }}=-1118.516518$ Hartree

Imaginary frequency: $-372.3 \mathrm{~cm}^{-1}$

\begin{tabular}{|c|c|c|c|}
\hline $\mathrm{C}$ & -6.01009900 & -0.37007400 & -1.62776500 \\
\hline & -5.19958800 & -1.17886400 & -0.61061700 \\
\hline & -3.83469100 & -0.54999000 & -0.32202600 \\
\hline $\mathrm{C}$ & -2.89993000 & -1.43805100 & 0.55202500 \\
\hline $\mathrm{C}$ & -1.51059700 & -0.86353900 & 0.72980100 \\
\hline $\mathrm{C}$ & -0.38187100 & -1.14622300 & 0.00098100 \\
\hline $\mathrm{C}$ & 0.88671100 & -0.69130500 & 0.48406000 \\
\hline O & 2.14781100 & -1.03061400 & -0.02224800 \\
\hline $\mathrm{C}$ & 2.94217000 & 0.54122400 & -1.24705800 \\
\hline $\mathrm{C}$ & 2.87172600 & 1.75272600 & -0.53439500 \\
\hline $\mathrm{C}$ & 1.67351200 & 2.37900600 & -0.17979200 \\
\hline $\mathrm{C}$ & 0.42318600 & 1.92236500 & -0.57503700 \\
\hline $\mathrm{C}$ & -0.80759500 & 2.25276400 & 0.03188100 \\
\hline $\mathrm{C}$ & -1.95223200 & 1.58883500 & -0.31309900 \\
\hline $\mathrm{C}$ & -3.18292100 & 1.69900700 & 0.47666900 \\
\hline $\mathrm{C}$ & -3.51233600 & -1.71927700 & 1.93669000 \\
\hline $\mathrm{C}$ & 3.28781800 & -1.22894300 & 0.99050100 \\
\hline $\mathrm{C}$ & 4.63336300 & -1.57378300 & 0.32951100 \\
\hline $\mathrm{C}$ & 5.22704800 & -0.48866300 & -0.56771100 \\
\hline $\mathrm{C}$ & 4.27729500 & -0.03473300 & -1.68995300 \\
\hline $\mathrm{C}$ & -0.43320800 & -1.91319400 & -1.30324900 \\
\hline $\mathrm{O}$ & -3.42020100 & 2.58914500 & 1.26804600 \\
\hline $\mathrm{O}$ & -4.11896800 & 0.70598200 & 0.32039700 \\
\hline $\mathrm{O}$ & 3.38818100 & -0.16564500 & 1.92202100 \\
\hline $\mathrm{O}$ & 5.60848900 & 0.59490400 & 0.30058100 \\
\hline $\mathrm{H}$ & -6.17348600 & 0.64779000 & -1.26143300 \\
\hline $\mathrm{H}$ & -6.98673900 & -0.83165800 & -1.80910800 \\
\hline $\mathrm{H}$ & -5.48611100 & -0.30419200 & -2.58980600 \\
\hline $\mathrm{H}$ & -5.76008200 & -1.25824400 & 0.32688700 \\
\hline $\mathrm{H}$ & -5.03726400 & -2.20074700 & -0.97892200 \\
\hline $\mathrm{H}$ & -3.34021900 & -0.37671000 & -1.28652400 \\
\hline $\mathrm{H}$ & -2.82383200 & -2.38910600 & 0.00795800 \\
\hline $\mathrm{H}$ & -1.36827500 & -0.29273800 & 1.64483300 \\
\hline
\end{tabular}




$\begin{array}{crrc}\mathrm{H} & 0.88632700 & -0.14667700 & 1.42486900 \\ \mathrm{H} & 2.16534900 & -1.76370600 & -0.83123000 \\ \mathrm{H} & 2.14096500 & 0.35018500 & -1.95510800 \\ \mathrm{H} & 3.78366900 & 2.14013200 & -0.09200600 \\ \mathrm{H} & 1.71715500 & 3.19359100 & 0.54213500 \\ \mathrm{H} & 0.37018900 & 1.21749400 & -1.40082200 \\ \mathrm{H} & -0.82745600 & 2.91967600 & 0.89193100 \\ \mathrm{H} & -1.94211100 & 0.95709500 & -1.19113000 \\ \mathrm{H} & -3.71258600 & -0.77978800 & 2.46210000 \\ \mathrm{H} & -2.82149800 & -2.31327600 & 2.54405400 \\ \mathrm{H} & -4.45298100 & -2.27266400 & 1.85914800 \\ \mathrm{H} & 3.00758900 & -2.10530500 & 1.59274900 \\ \mathrm{H} & 4.51112700 & -2.48529300 & -0.26998800 \\ \mathrm{H} & 5.35725900 & -1.79594800 & 1.12099300 \\ \mathrm{H} & 6.13281500 & -0.89723200 & -1.04323300 \\ \mathrm{H} & 4.10311100 & -0.90292500 & -2.33812400 \\ \mathrm{H} & 4.80490200 & 0.70390300 & -2.31417700 \\ \mathrm{H} & 0.11407700 & -2.86206100 & -1.23618200 \\ \mathrm{H} & 0.03451800 & -1.33419800 & -2.11025700 \\ \mathrm{H} & -1.45504200 & -2.13880700 & -1.61639200 \\ \mathrm{H} & 3.97499800 & 0.50325900 & 1.53014100 \\ \mathrm{H} & 5.99620900 & 1.29923300 & -0.24237600 \\ & & & \end{array}$

\section{TS-2}

$G_{\text {water }}=-1118.544415$ Hartree

Imaginary frequency: $-269.5 \mathrm{~cm}^{-1}$

$\begin{array}{lrrc}\mathrm{C} & -6.08939000 & -0.48829600 & -1.54669400 \\ \mathrm{C} & -5.21959600 & -1.22154000 & -0.52099300 \\ \mathrm{C} & -3.85736000 & -0.55404300 & -0.33118200 \\ \mathrm{C} & -2.86043200 & -1.36406000 & 0.54718100 \\ \mathrm{C} & -1.50063000 & -0.69755400 & 0.66247800 \\ \mathrm{C} & -0.35787700 & -0.98794800 & -0.07907000 \\ \mathrm{C} & 0.84947000 & -0.35564200 & 0.27778300 \\ \mathrm{C} & 2.20319000 & -0.74121200 & -0.25984500 \\ \mathrm{C} & 2.93342000 & 0.35146700 & -1.15054900 \\ \mathrm{C} & 2.92435000 & 1.71450600 & -0.51799200 \\ \mathrm{C} & 1.76478700 & 2.34520100 & -0.25370600 \\ \mathrm{C} & 0.48413800 & 1.75961900 & -0.61208600 \\ \mathrm{C} & -0.72669300 & 2.10601000 & -0.00470000 \\ \mathrm{C} & -1.90188600 & 1.45675900 & -0.33408000 \\ \mathrm{C} & -3.13992300 & 1.66540400 & 0.42938900 \\ \mathrm{C} & -3.42203900 & -1.62585000 & 1.95619100\end{array}$




\begin{tabular}{|c|c|c|c|}
\hline $\mathrm{C}$ & 3.10707500 & -1.19557200 & 0.92621100 \\
\hline $\mathrm{C}$ & 4.47459800 & -1.69277400 & 0.43018300 \\
\hline $\mathrm{C}$ & 5.20907800 & -0.64787500 & -0.41012600 \\
\hline $\mathrm{C}$ & 4.33144700 & -0.15136300 & -1.56668600 \\
\hline $\mathrm{C}$ & -0.44019600 & -1.76421400 & -1.37887300 \\
\hline $\mathrm{O}$ & -3.33310300 & 2.57208200 & 1.21254000 \\
\hline $\mathrm{O}$ & -4.13159000 & 0.73121700 & 0.25393800 \\
\hline $\mathrm{O}$ & 3.23866200 & -0.19375600 & 1.92288900 \\
\hline $\mathrm{O}$ & 5.57685600 & 0.41549700 & 0.49247800 \\
\hline $\mathrm{H}$ & -6.25543000 & 0.54688400 & -1.23388400 \\
\hline $\mathrm{H}$ & -7.06415500 & -0.97560300 & -1.65653800 \\
\hline $\mathrm{H}$ & -5.60928000 & -0.47121300 & -2.53334500 \\
\hline $\mathrm{H}$ & -5.73655900 & -1.25391300 & 0.44386300 \\
\hline $\mathrm{H}$ & -5.05323800 & -2.26078900 & -0.83515900 \\
\hline $\mathrm{H}$ & -3.40936200 & -0.42284300 & -1.32561700 \\
\hline $\mathrm{H}$ & -2.74334600 & -2.32877000 & 0.03571100 \\
\hline $\mathrm{H}$ & -1.33711800 & -0.18047900 & 1.60447200 \\
\hline $\mathrm{H}$ & 0.89397200 & 0.10126500 & 1.26081200 \\
\hline $\mathrm{H}$ & 2.09594500 & -1.61397200 & -0.91850800 \\
\hline $\mathrm{H}$ & 2.33852200 & 0.40168500 & -2.07335700 \\
\hline $\mathrm{H}$ & 3.86553500 & 2.15099900 & -0.20014400 \\
\hline $\mathrm{H}$ & 1.76148600 & 3.27538900 & 0.31272500 \\
\hline $\mathrm{H}$ & 0.42654000 & 1.25003400 & -1.57237800 \\
\hline $\mathrm{H}$ & -0.72028800 & 2.72421700 & 0.89164900 \\
\hline $\mathrm{H}$ & -1.96119300 & 0.93178600 & -1.27977000 \\
\hline $\mathrm{H}$ & -3.66509600 & -0.68018000 & 2.45186100 \\
\hline $\mathrm{H}$ & -2.68340900 & -2.15456300 & 2.56778800 \\
\hline $\mathrm{H}$ & -4.32941400 & -2.23628300 & 1.92302500 \\
\hline $\mathrm{H}$ & 2.59477500 & -2.03026900 & 1.42053500 \\
\hline $\mathrm{H}$ & 4.33687000 & -2.59363400 & -0.18156500 \\
\hline $\mathrm{H}$ & 5.09086600 & -1.96538800 & 1.29349900 \\
\hline $\mathrm{H}$ & 6.12629100 & -1.09418100 & -0.82471900 \\
\hline $\mathrm{H}$ & 4.21538600 & -0.98913300 & -2.26792600 \\
\hline $\mathrm{H}$ & 4.85859500 & 0.63912200 & -2.11969800 \\
\hline $\mathrm{H}$ & 0.12358300 & -2.70456800 & -1.33026800 \\
\hline $\mathrm{H}$ & -0.01756900 & -1.18292300 & -2.20891200 \\
\hline $\mathrm{H}$ & -1.46820100 & -2.01437500 & -1.65144700 \\
\hline $\mathrm{H}$ & 3.94138400 & 0.41180500 & 1.62767100 \\
\hline $\mathrm{H}$ & 6.00758700 & 1.11621800 & -0.02139700 \\
\hline
\end{tabular}




\section{References}

(1) Frisch, M. J.; Trucks, G. W.; Schlegel, H. B.; Scuseria, G. E.; Robb, M. A.; Cheeseman, J. R.; Scalmani, G.; Barone, V.; Mennucci, B.; Petersson, G. A.; Nakatsuji, H.; Caricato, M.; Li, X.; Hratchian, H. P.; Izmaylov, A. F.; Bloino, J.; Zheng, G.; Sonnenberg, J. L.; Hada, M.; Ehara, M.; Toyota, K.; Fukuda, R.; Hasegawa, J.; Ishida, M.; Nakajima, T.; Honda, Y.; Kitao, O.; Nakai, H.; Vreven, T.; Montgomery, J. A., Jr.; Peralta, J. E.; Ogliaro, F.; Bearpark, M.; Heyd, J. J.; Brothers, E.; Kudin, K. N.; Staroverov, V. N.; Kobayashi, R.; Normand, J.; Raghavachari, K.; Rendell, A.; Burant, J. C.; Iyengar, S. S.; Tomasi, J.; Cossi, M.; Rega, N.; Millam, J. M.; Klene, M.; Knox, J. E.; Cross, J. B.; Bakken, V.; Adamo, C.; Jaramillo, J.; Gomperts, R.; Stratmann, R. E.; Yazyev, O.; Austin, A. J.; Cammi, R.; Pomelli, C.; Ochterski, J. W.; Martin, R. L.; Morokuma, K.; Zakrzewski, V. G.; Voth, G. A.; Salvador, P.; Dannenberg, J. J.; Dapprich, S.; Daniels, A. D.; Farkas, O.; Foresman, J. B.; Ortiz, J. V.; Cioslowski, J.; Fox, D. J. Gaussian 09, revision D.01; Gaussian, Inc.: Wallingford, CT, 2013.

(2) Grimme, S.; Antony, J.; Ehrlich, S.; Krieg, H. A consistent and accurate ab initio parametrization of density functional dispersion correction (DFT-D) for the 94 elements $\mathrm{H}-\mathrm{Pu}$. J. Chem. Phys. 2010, 132, 154104.

(3) Zhao, Y.; Truhlar, D. G. The M06 suite of density functionals for main group thermochemistry, thermochemical kinetics, noncovalent interactions, excited states, and transition elements: two new functionals and systematic testing of four M06-class functionals and 12 other functionals. Theor. Chem. Acc. 2008, 120, 215-241.

(4) Barone, V.; Cossi, M. Quantum calculation of molecular energies and energy gradients in solution by a conductor solvent model. J. Phys. Chem. A 1998, 102, 1995-2001.

(5) Cossi, M.; Rega, N.; Scalmani, G.; Barone, V. Energies, Structures, and electronic properties of molecules in solution with the C-PCM solvation model. J. Comput. Chem. 2003, 24, 669-681.

(6) Zhang, B.; Wang, K. B.; Wang, W.; Wang, Xin; Liu, F.; Zhu, J. P.; Shi, J.; Li, L. Y.; Han, H.; Xu, K.; Qiao, H. Y.; Zhang, X.; Jiao, R. H.; Houk, K. N.; Liang, Y.; Tan, R. X.; Ge, H. M. Enzyme-catalysed [6+4] cycloadditions in the biosynthesis of natural products. Nature 2019, $568,122-126$.

(7) Trott, O.; Olson, A. J. AutoDock Vina: improving the speed and accuracy of docking with anew scoring function, efficient optimization and multithreading. J. Comput. Chem. 2010, 31, 455-461.

(8) Case, D. A.; Berryman, J. T.; Betz, R. M.; Cerutti, D. S.; Cheatham, T. E., III; Darden, T. A.; Duke, R. E.; Giese, T. J.; Gohlke, H.; Götz, A. W.; Homeyer, N.; Izadi, S.; Janowski, P. A.; Kaus, J. W.; Kovalenko, A.; Lee, T.; Le Grand, S.; Li, P.; Luchko, T.; Luo, R.; Madej, B. D.; Merz, K. M.; Monard, G.; Needham, H.; Nguyen, H.; Nguyen, H. T.; Omelyan, I.; Onufriev, A.; Roe, D. R.; Roitberg, A. E.; Salomon-Ferrer, R.; Simmerling, C.; Smith, W.; Swails, J.; Walker, R. C.; Wang, J.; Wolf, R. M.; Wu, X.; York, D. M.; Kollman, P. A. AmberTools 16, University of California, San Francisco, 2016.

(9) Bayly, C. I.; Cieplak, P.; Cornell, W.; Kollman, P. A. A well-behaved electrostatic potentialbased method using charge restraints for deriving atomic charges: the RESP model. $J$. Phys. Chem. 1993, 97, 10269-10280. 
(10) Wang, J.; Wolf, R. M.; Caldwell, J. W.; Kollman, P. A.; Case, D. A. Development and testing of a general AMBER force field. J. Comput. Chem. 2004, 25, 1157-1174.

(11) Lindorff-Larsen, K.; Piana, S.; Palmo, K.; Maragakis, P.; Klepeis, J. L.; Dror, R. O.; Shaw, D. E. Improved side-chain torsion potentials for the Amber ff99SB protein force field. Proteins 2010, 78, 1950-1958.

(12) Frisch, M. J.; Trucks, G. W.; Schlegel, H. B.; Scuseria, G. E.; Robb, M. A.; Cheeseman, J. R.; Scalmani, G.; Barone, V.; Petersson, G. A.; Nakatsuji, H.; Li, X.; Caricato, M.; Marenich, A. V.; Bloino, J.; Janesko, B. G.; Gomperts, R.; Mennucci, B.; Hratchian, H. P.; Ortiz, J. V.; Izmaylov, A. F.; Sonnenberg, J. L.; Williams-Young, D.; Ding, F.; Lipparini, F.; Egidi, F.; Goings, J.; Peng, B.; Petrone, A.; Henderson, T.; Ranasinghe, D.; Zakrzewski, V. G.; Gao, J.; Rega, N.; Zheng, G.; Liang, W.; Hada, M.; Ehara, M.; Toyota, K.; Fukuda, R.; Hasegawa, J.; Ishida, M.; Nakajima, T.; Honda, Y.; Kitao, O.; Nakai, H.; Vreven, T.; Throssell, K.; Montgomery, J. A., Jr.; Peralta, J. E.; Ogliaro, F.; Bearpark, M.; Heyd, J. J.; Brothers, E. N.; Kudin, K. N.; Staroverov, V. N.; Kobayashi, R.; Normand, J.; Raghavachari, K.; Rendell, A.; Burant, J. C.; Iyengar, S. S.; Tomasi, J.; Cossi, M.; Millam, J. M.; Klene, M.; Adamo, C.; Cammi, R.; Ochterski, J. W.; Martin, R. L.; Morokuma, K.; Farkas, O.; Foresman, J. B.; Fox, D. J. Gaussian 16, revision A.03; Gaussian, Inc.: Wallingford CT, 2016.

(13) Yang, Z.; Yang, S.; Yu, P.; Li, Y.; Doubleday, C.; Park, J.; Patel, A.; Jeon, B. S.; Russell, W. K.; Liu, H. W.; Russell, D. H.; Houk, K. N. Influence of water and enzyme SpnF on the dynamics and energetics of the ambimodal $[6+4] /[4+2]$ cycloaddition. Proc. Natl. Acad. Sci. U. S. A. 2018, 115, E848-E855.

(14) Biswas, B.; Collins, S. C.; Singleton, D. A. Dynamics and a unified understanding of competitive [2, 3]- and [1, 2]-sigmatropic rearrangements based on a study of ammonium ylides. J. Am. Chem. Soc. 2014, 136, 3740-3743.

(15) Götz, A. W.; Clark, M. A.; Walker, R. C. An extensible interface for QM/MM molecular dynamics simulations with AMBER. J. Comput. Chem. 2014, 35, 95-108.

(16) McGibbon, R. T.; Beauchamp, K. A.; Harrigan, M. P.; Klein, C.; Swails, J. M.; Hernández, C. X.; Schwantes, C. R.; Wang, L.-P.; Lane, T. J.; Pande, V. S. MDTraj: A modern open library for the analysis of molecular dynamics trajectories. Biophys. J. 2015, 109, $1528-1532$.

(17) CYLview, 1.0b; Legault, C. Y., Université de Sherbrooke, 2009 (http://www.cylview.org).

(18) Wallace, A. C.; Laskowski, R. A.; Thornton, J. M.; Wallace, A. C.; Laskowski, R. A.; Thornton, J. M. LIGPLOT: a program to generate schematic diagrams of protein-ligand interactions. Protein Eng. 1995, 8, 127-134.

(19) Sambrook, J.; Russell, D. W. Molecular cloning: a laboratory manual (3rd edn.); Cold Spring Harbor Laboratory Press: New York, 2001.

(20) Zhang, B.; Wang, K. B.; Wang, W.; Bi, S. F.; Mei, Y. N.; Deng, X. Z.; Jiao, R. H.; Tan, R. X.; Ge, H. M. Discovery, biosynthesis, and heterologous production of streptoseomycin, an anti-microaerophilic bacteria macrodilactone. Org. Lett. 2018, 20, 2967-2971.

(21) Kieser, T.; Bibb, M. J.; Buttner, M. J.; Chater, K. F.; Hopwood, D. A. Practical Streptomyces genetics; The John Innes Foundation: Norwich, 2000. 
(22) Li, L.; Pan, G.; Zhu, X.; Fan, K.; Gao, W.; Ai, G.; Ren, J.; Shi, M.; Olano, C.; Salas, J. A.; Yang, K. Engineered jadomycin analogues with altered sugar moieties revealing JadS as a substrate flexible O-glycosyltransferase. Appl. Microbiol. Biot. 2017, 101, 5291-5300.

(23) Green M. R.; Sambrook J. Molecular Cloning: A Laboratory Manual 4th ed. Cold Spring Harbor Laboratory Press, 2012.

(24) Bierman, M.; Logan, R.; O’Brien, K.; Seno, E. T.; Rao, R. N.; Schoner, B. E. Plasmid cloning vectors for the conjugal transfer of DNA from Escherichia coli to Streptomyces spp.

Gene 1992, 116, 43-49. 